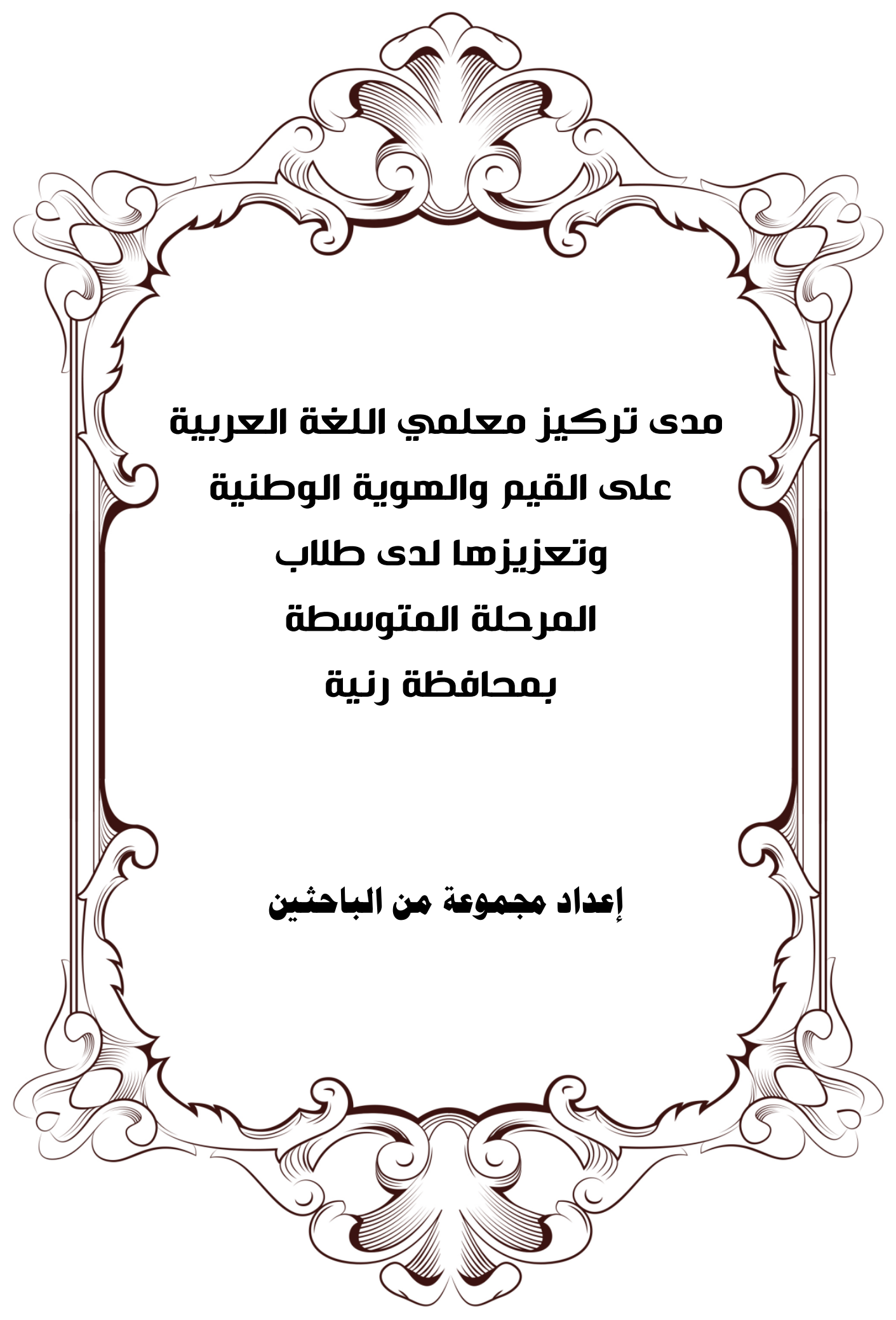



مدى تركيز معلمي اللغت العربيت على القيم والهويت الوطنيت وتعزيزها لدى طلاب المرحلت

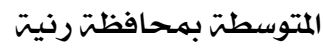

حوليتة كليتت اللغت العربيت بإيتاي البارود (العدد الثالث والثلاثون)

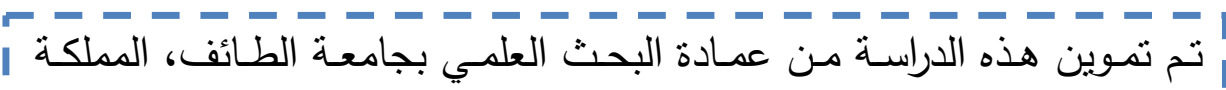

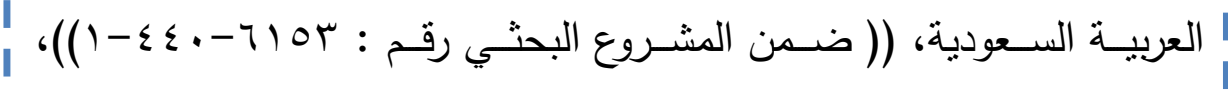

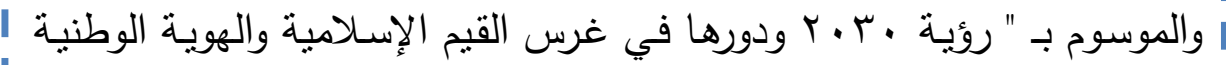

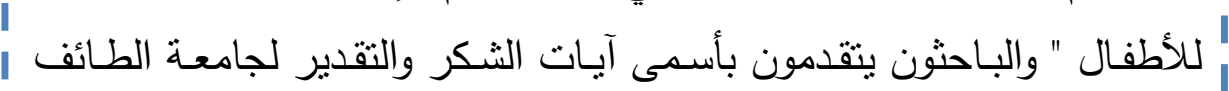

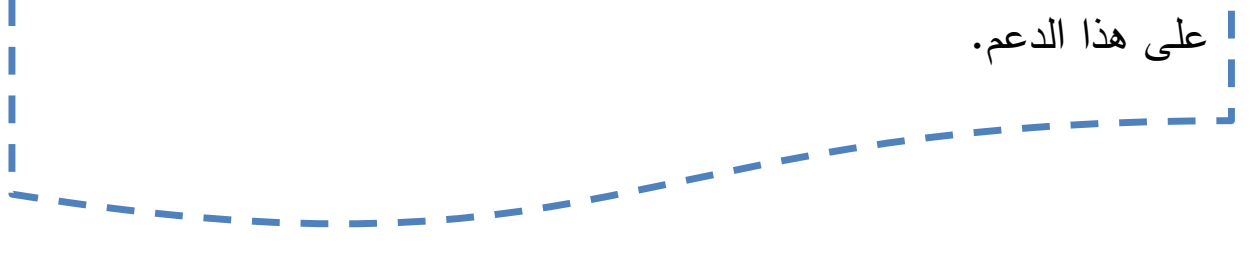


حوليت كليت اللغت العربيت بإيتاي البارود (العدد الثالث والثلاثون)

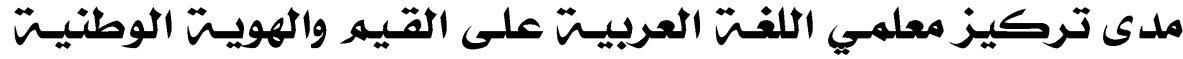

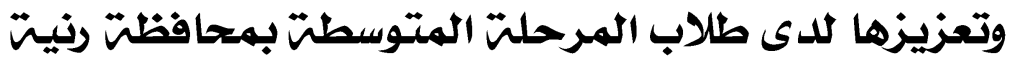
مسفر سعود مبارك الهرثي.

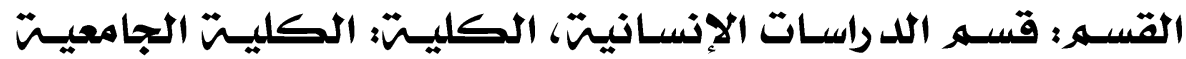

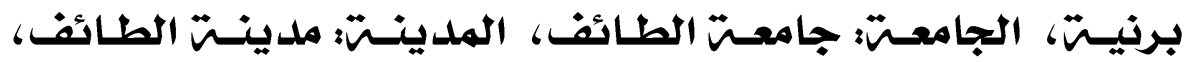

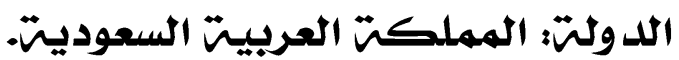
البريل الاكتكتروني: m.alhersh@tu.edu.sa

الباحث الرئيس

محمد علي حسن حسن الشوكي.

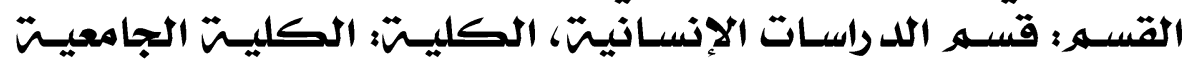

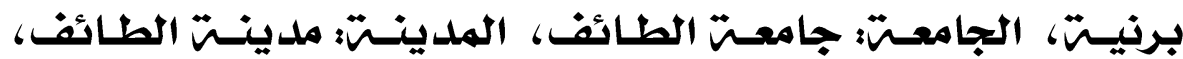

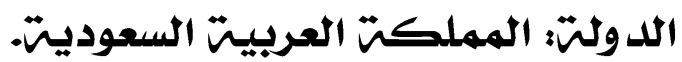

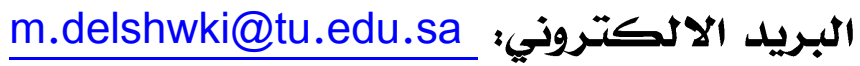

باحث مشارك

محمد عبد العزيز الفارس السبيعي.

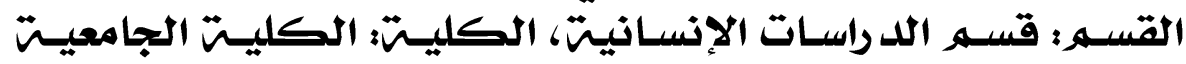

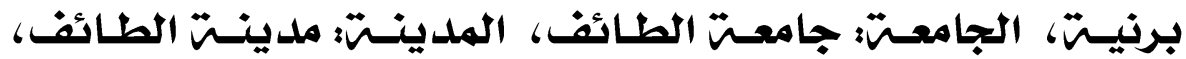

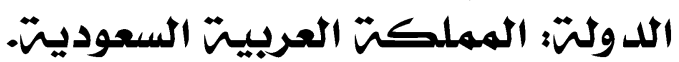
البريل الالكتروني: m.alfaris@tu.edu.sa

باحث مشارك

عبد العزيز بن عيضت البنيوسي الحارثي.

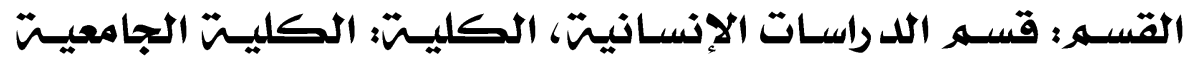

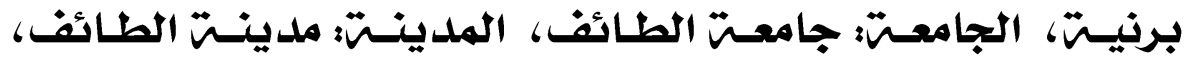

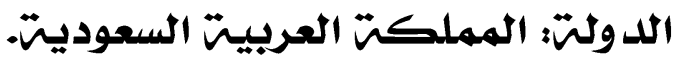

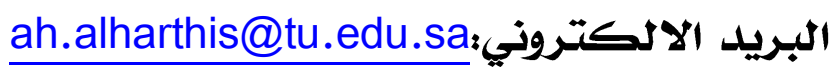

باحث مشارك

أشرف علي عبد الرحيهر محمد رشوان.

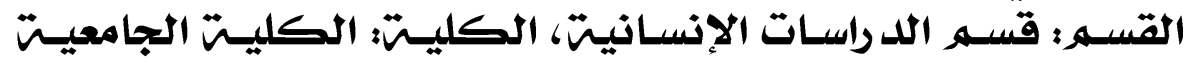

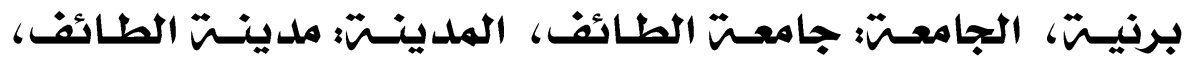

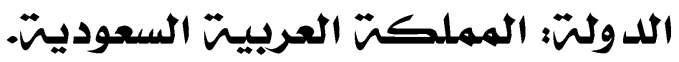
البريل الالكتروني: a.ashraff@tu.edu.sa 
حوليتة كليت اللغت العربيت بإيتاي البارود (العدد الثالث والثلاثون)

\section{باحث مشارك}

أحمد عبل الرحييم حسنين مربي.

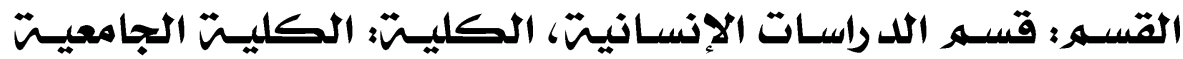

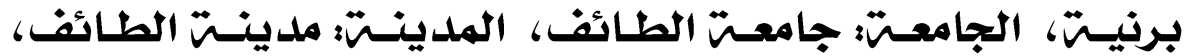

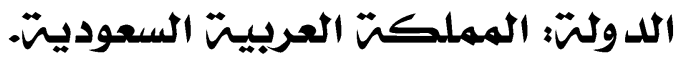
البربيد الالكتروني:

باحث مشارك

ملخص: هدفت الدراسـة إلى التعرف على مدى تركيز معلمي اللغـة العربية على القيم والهوبـة الوطنية وتعزيزها لدى طلاب المرحلة المتوسطة بمحافظة رنيـة بالمملكة العربية السـودية " من وجهة نظر المعلمين أنفسهم، اعتمدت الدراسة المنهج الوصفي، ولتحقيق أهداف الدراسـة أعد الباحث استبانة تكونت من ( (Y) فقرة تمثل كل فقرة سلوكاً أو قيماً وطنية يسعى المعلم إلى تعزيزها لدى الطلاب، توزعت على ثلاة أبعاد، هي: (الانتماء والهوبة الوطنبة، الالتزام بمعـايير وقيم المجتمـع، المسؤولية الوطنبـة تجـاه المجتمـع)، وتكونـت عينـة الدراسة من جميع معلي اللغة العربية في المدارس المتوسطة بمحافظة رنية والبـالغ عددهم (7^) معلمـاً. أظهرت نتائج البحـث أن معلمهي اللغـة العربيـة يركزون بدرجة مرتفعة على القيم والهوية الوطنية وتعزيزها لدى طلاب المرحلة المتوسطة بمحافظة رنية بالمملكة العربية السعودية، كما بينت النتائج أن مدى تركيز معلمي اللغـة العربيـة على أبعاد الدراسـة (الكلي) "مرتفعاً"، حيـث جـاء الأعلى في التركيز بعد "الانتمـاء الوطني والهوبـة الوطنيـة"، يليه بعد "الالتزام بمعـايير وقيم المجتمـع"، وثالثناً بعد " المسؤولية الوطنيـة تجـاه المجتمـع"، مـع العلم أن جميع الأبعاد كانت ذات متوسط حسابي أعلى من المستوى المقبول

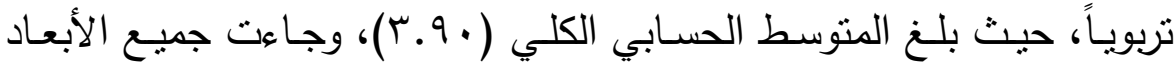
بدرجة مرتفعة من التركيز • وفي ضوء نتائج البحث أوصسى الباحث بضرورة الاستمرار بالإعداد الجيـد لمعلمي اللغـة العربية والمـواد الدراسية الأخرى من أجـل تعميـق روح المواطنـة لـدى الطـلاب في المراحل التعليميـة المختلفـة. 
مدى تركيز معلمي اللغت العربيت على القيم والهويت الوطنيت وتعزيزها لدى طلاب المرحلت

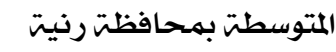

$$
\text { حوليتة كليت اللغت العربيتت بإيتاي البارود (العدد الثالث والثلاثون) }
$$

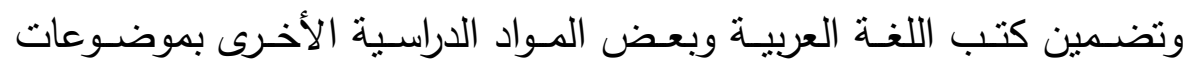
تعليمية وطنية تعزز روح الولاء والانتماء، وإجراء دراسات مماثلة على معلمي ومعلمات مواد دراسية أخرى لها علاقة بتعزيز القيم الوطنية والهوبية الوطنبة لدى الطلاب، كمادة التربية الوطنية، والتربية الإسلامية. الكلمات المفتاحية: القيم، الهوبة الوطنية، تركيز، معلمو اللغة العربية. 
مدى تركيز معلمي اللغتَ العربيت على القيه والهويت الوطنيت وتعزيزها لدى طلاب المرحلتً

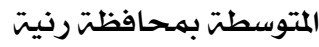

حوليت كليت اللغتا العربيتشبايتاي البارود (العدد الثالث والثلاثون)

The Extent of the focus of Arabic language teachers on

the values and national identity and its promotion

among middle school students in Reniyah

Misfer Saud Mubarak Al-Harsh.

Department: Human Studies Department, College: University College Berne, University: Taif University, City: Taif City, Country: Kingdom of Saudi Arabia.

Email: m.alhersh@tu.edu.sa

Principal Investigator

Muhammad Ali Hassan Hassan Al-Shawky.

Department: Humanities Studies Department, College: University College in Barnia, University: Taif University, City: Taif City, Country: Kingdom of Saudi Arabia.

Email:m.delshwki@tu.edu.sa

Associate Researcher

Mohammed Abdul Aziz Al-Faris Al-Subaie.

Department: Humanities Studies Department, College: University College in Barnia, University: Taif University, City: Taif City, Country: Kingdom of Saudi Arabia.

Email: m.alfaris@tu.edu.sa

Associate Researcher

Abdul Aziz bin Eidah Al-Binousi Al-Harthy.

Department: Human Studies Department, College: University College Berne, University: Taif University, City: Taif City, Country: Kingdom of Saudi Arabia.

Email: ah.alharthis@tu.edu.sa

Associate Researcher

Ashraf Ali Abdul Rahim Mohammed Rashwan.

Department: Human Studies Department, College: University College Berne, University: Taif University, City: Taif City, Country: Kingdom of Saudi Arabia.

Email: a.ashraff@tu.edu.sa

Associate Researcher

Ahmed Abdel Rahim Hassanein Morsi. 
حوليت كليت اللغتّالعربيتبايتاي البارود (العدد الثالث والثلاثون)

Department: Humanities Studies Department, College: University College in Barnia, University: Taif University, City: Taif City, Country: Kingdom of Saudi Arabia.

Email: a.abdoo@tu.edu.sa

Associate Researcher

Abstract: The aim of this study is to determine the extent to which Arabic language teachers focus on values, national identity and promotion among middle school students in Rania province, Saudi Arabia. From the point of view of teachers themselves, the study adopted the descriptive approach, and to achieve the objectives of the study the researcher prepared a questionnaire consisting of (21) paragraphs representing each paragraph national behavior or values that the teacher seeks to promote among students, distributed on three dimensions They are: (belonging and national identity, commitment to the standards and values of society, national responsibility towards society)، The sample of the study consisted of all the teachers of Arabic language in the middle schools in the governorate of Raniyeh and the number of (68) teachers. The results of the research showed that the Arabic language teachers are highly focused on the values and national identity and promotion among middle school students in the province of Raniyah, Saudi Arabia, The results also showed that the extent of the focus of Arabic language teachers on the dimensions of the study (total) "high", where the highest in the focus after "national belonging and national identity", followed by "commitment to the standards and values of society", Thirdly, after the "national responsibility towards society", knowing that all dimensions had an arithmetic average higher than the educationally acceptable level, where the total arithmetic average was (3.90), and all dimensions came with a high degree of concentration. In light of the results of the 
مدى تركيز معلمي اللغت العربيت على القيم والهويت الوطنيت وتعزيزها لدى طلاب المرحلت

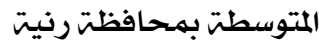

حوليت كليت اللغت العربيت بإيتاي البارود (العدد الثالث والثلاثون)

research, the researcher recommended the necessity of continuing to prepare well for Arabic language teachers and other subjects in order to deepen the spirit of citizenship among students at different educational levels. Include Arabic textbooks and other subjects in national educational subjects that promote loyalty and belonging, and conduct similar studies on teachers and other subjects related to the promotion of national values and national identity among students, such as civic education and Islamic education.

Keywords: Arabic Language Teachers, National Identity, Values. 
حوليتة كليتت اللغت العربيت بإيتاي البارود (العدد الثالث والثلاثون)

\section{المقدهمة}

الوطن ليس منطقـة جغرافيـة تحتوبي على أرض وتراب حسبـ، وإنمـا تعدى ذلك بكثير أيضـاً، فقد دخل في الوجدان الإنسـاني والعاطفة الإنسـانية

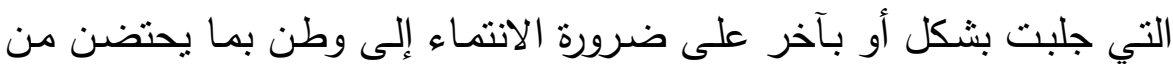
أرض وقيم وتطلعات، وعليه فإن مفهوم الوطن يشتمل الجانب المـادي الذي

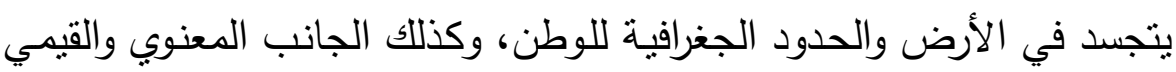
الذي يتجسد في طبيعـة القيم والمبادئ والمثل الذي يعتنقها المجتمع وتسعى التوجهات الوطنية إلى تجسيدها عبر برامج تعليمية ومشروعات وطنية متعددة،

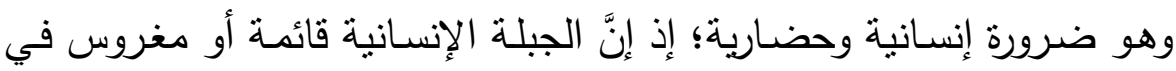

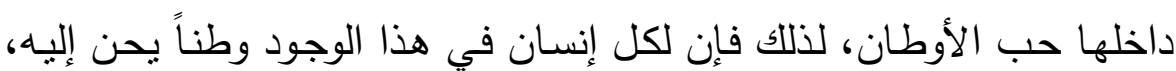
ويعمل على منحه كل شروط القوة والعزة ومواصفاتها. وإذ يعد طلاب المدارس وطالباتها أهم مكون بشري للمجتمع، فمن خلالهم يستطيع المجتمع أن يحقق جميع آمالها وتطلاتها المستقبلية، وعلى عاتقهم يتحملون نهضته وتقدمه، لذلك فقد استثرت الدولة السعودية الأموال الطائلة في التعليم بشـكل عـام، بهـدف المصـلحة العامـة للفـرد والـوطن. ومـن هــا

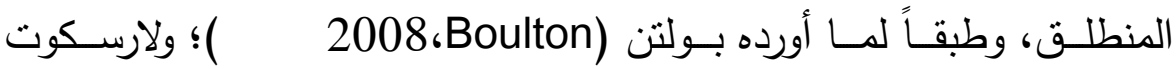
Larasquet التعليم المختلفة في مواجهة تأثيرات تعاظم المعرفة وثورة الاتصالات والعولمة الوطنيـة والثقافيـة على النشء والمجتمع، وذللك لأن الطـلاب هم أهم مكون مستهدف داخل المؤسسة التعليمية، فإنه من الضروري ضمان انتمائهم وغرس هوية المواطنة وقيمها في شخصيتهم، وبالتالي، فإن عملية بناء القيم والهوية

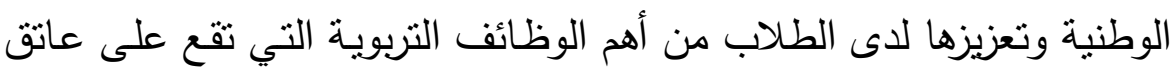

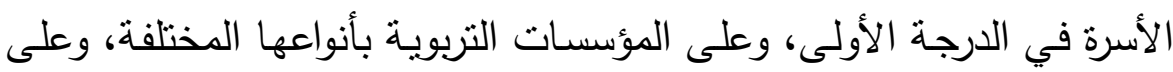
المدرسة والمعلمين على وجه التحديد ( الثنيتي، 0 ـ ب). 
حوليتة كليت اللغت العربيت بايتاي البارود (العدد الثالث والثلاثون)

وإذ تعد مرحلـة التعليم المتوسطة في المملكة العربيـة السـودية مـن أهـم

المراحل التعليمبـة التي يمكن أن تتم فيها تعزبز القيم والهوبـة الوطنيـة للطلاب، كونها تمنت المرحلة العمرية المهمة في حباة الطالب، والتي ثتراوح ما بين (1) 1 ) سنة، إذ يتصفون في هذا العمر بقدرات عقليـة ومهاربـة وقيمبـة تسـاعدهم على بناء منظومتهم الوطنية والقيمية لتكون جزءاً من شخصيتهم في ممارساتهم ومعاملاتهم الحياتية المختلفة، باعتبار أن الطلاب بحاجة إلى تعزيز الوعي لديهم بأهميـة تمثنل القيم الوطنيـة المختلفـة، والعمـل على ممارسـتها وتأصـيلها فكـراً ومعتقداً وسـوكاً، تجنبـاً للتأثز السـلبي بعصـر المعرفـة والتقنيـة والاتصـال التي فرضت نفسها على كافة المجتمعات بما تحمله من أفكار وتوجهات فكربة وقيمية والتي قد لا تتواءم مـع المنظومسة القيمية والوطنيـة التي تعمل المدرسـة ومعلميها على تعزبزها لاى الطلاب، باعتبار الطلاب أكبر فئات المجتمع وأهمها، وعليهم تعلق آمـال المجتمـع وتقدمهـ ورقيـه، كان لابـد من التركيز على بنـاء المنظومـة القيميـة الوطنبـة وتعزيزهـا عندهم، وترسـيخها بصـورة تلبـق بـدورهم الاجتمـاعي والوطني من أجل خدمة المجتمع المحلي وتطوبره ( طلافحة، ب ا • ب). وتُعـدُّ مـادة اللغـة العربيـة مسن أهم المـواد التعليميـة التي تقدم للطـلاب في المدارس، فهي إحدى المواد التعليمية الهادفة إلى اكتسـاب مهارة اللغـة العربيـة والتي من خلالها تنم عملية تعزيز الحس الوطني وقيم المواطنة لدى الطلاب، وذللك بتضافر جهود المدرسة والأسرة والمجتمع ووسائل الإعلام، نحو تعزيز القيم والهوبة الوطنية وتتشئة المواطن الصالح المتصف بعدة صفات منها : الاعتزاز والانتماء والولاء للوطن والأمسة العربية والإسـلامية، والالتزام بقوانين الدولة وأنظمتها، والالتزام بمبادئ العدالة الاجتماعية والتحرر من التعصب والغلو، وتعزيز القيم والهوبة الوطنية التي تمكن المواطن من ممارسة أدواره على أكمل

$$
\text { وجه ( الرشيدي، } 1 \text { ( • (Y). }
$$


حوليتة كليت اللغتّ العربيت بإيتاي البارود (العدد الثالث والثلاثون)

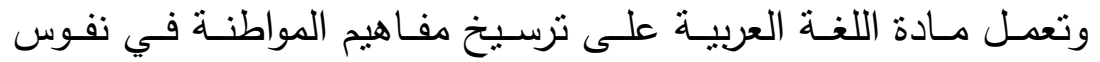

الطلاب، واكتساب قيم العمل التطوعي وتحمل المسؤولية والتعامل مـع الآخر ،

وغيرها من القيم الاجتماعية والوطنية التي لها دورٌ مههم في إكسابهم أسـاليب التعامـل مـع متغيـرات وتحديات العصـر ، إضـافةً إلى دورهـا في زيـادة الوعي بأثـكاله كافـة لـدى الطـلاب سـواء على المسـتوى المحلي أو الاجتمـــي أو السياسـي أو البيئي، وذلـك بمـا تتضـمنه مـن موضـوعات وأسـاليب تعليميـة ووسائل التنثئة الاجتماعية والوطنية للطلاب، وإذا كانت المدارس و من أهم مؤسسات نتشئة الطلاب وإعدادهم فإن ذلك يحملها مسئولية توظيف ممارستها التربوبـة مسن أجل إرسـاء مبادئ التربيـة الوطنيـة لدى أبناء المجتمـع بمختلف أعمارهم، للإسـهام في بناء المواطن الصسالح في ذاته والمصلح لغيره، والقادر على النهوض بالمجتمع (جابر ، 11 . وإنّ دراسـة الأداء الوطني والقيمي للمدرسـة بشكل عام ولمعلم اللغة العربية بشكل خاص يشكل مقدمة ضرورية لتقصي مدى تركيز واهتمام معلمي اللغة العربية بتعزيز الهوية الوطنية ومنظومهة القيم الاجتماعية لدى الطلاب، وذلك انطلاقا من أهمية العلاقة الوثيقة بين المدرسة والطلاب (الهجلة، $\cdot(r \cdot) \varepsilon$

فاللغة العربية تشكل الصورة الوطنية والقيمية المستقبلية التي سيكون عليها هذا المجتمع، إذ لم يعد دور المدارس والمؤسسات التربوية في إطار المجتمع المعاصر قاصراً على تقديم معرفة أو ثقافة إنسانية عامة ثم تلقين الطلاب هذه المعرفة فقط ، بل أصبح هذا الدور معنيا بأداء مهمات جديدة تستجيب لحاجات مجتمعية ووطنية متجددة، وهذا يعني إن المههة الأساسية للمدرسـة وللمعلم ثتمحور حول بناء شخصية الطالب الصالح الذي يستطيع ان يتجاوب

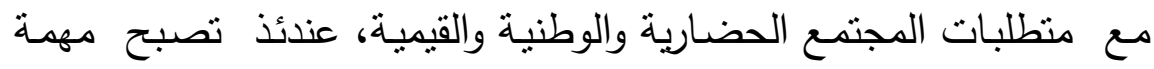
المدرسة والمعلم تربية الطلاب على ممارسـة المفاهيم والقيم الوطنية كأسلوب 
حوليتة كليتت اللغت العربيت بإيتاي البارود (العدد الثالث والثلاثون)

حياة، وهذا لا يحدث إلا إذا كانت بيئة المدرسـة تتسم بممارسـة حقيقية للقيم

$$
\text { الوطنية ( العظامات، r ب ( ب ). }
$$

ويمكن أن تدعم المدرسـة ومعلموها الانتماء الوطني والهوبة الوطنية

لدى الطلاب بالحب والتفاعل فيما بينهم ومع المعلمين والبيئة المجتمعية المحيطة بهم، واشثباع رغباتهم ومراعاة ميولهم في إطار المنظومة القيمية للمجتمع، فالمدرسة التي لا تراعي ذلك لا تستطيع أن تغرس في نفوس طلابها الانتماء الوطني العميق، مما يتوجب على معلمي اللغة العربية التأكيد على القيم والهويـة الوطنبـة، وضـرورة تعزيزهـا لدى الطـلاب من خـلل موضـوعات اللغـة العربيـة التعليمبـة، والأنشطة المدرسية والمجتمعيـة الوطنبـة ، مـن أجل تشكيل الشخصية الواعية المنزنة لديهم (السرحان، ع ( • ب). لذا فان مفهوم القيم والهوبة الوطنية من المفاهيم المهمـة في مجتمعنا المعاصر التي يشار إليها في وسائل إعلامنا وفي المدارس ومؤسسات التعليم، وأصبح مفهومـاً رئيساً في الحيـاة العامـة (بـن عبدالله، ا • ب). ولقد تتـاول المهتمـون بأدبيات التربيـة موضـوع الهوبـة الوطنيـة والقيم الوطنيـة بـالبحوث

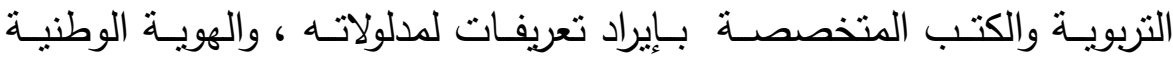
إحسـاس وشـعور وإدراك نفسي واجتمـاعي مـن جانـب المـواطن بأنـه جزء مـن وطنه، يحبه ويتعلق به وبكن له بالولاء، ويعدٌّ الانتماء الوطني اتجاها إيجابياً مدعماً بالحب يستشعره الفرد تجاه وطنه مؤكداً وجود ارتباط وانتساب نحو هذا الوطن باعتباره عضواً فيه، وبترجم في شكل من أشكال السلوك بمكن قياسـه

$$
\text { بالمواقف والأفعال" (إسماعيل وشحاته، ب ا • r). }
$$

وبنظر إلى الانتماء الوطني بأنه: "ثعور داخلي يجعل الإنسان يعمل

بحماس وإخلاص للارتقاء بوطنه وللافاع عنه على اختلاف تتوعه المجتمعي والديني والمذهبي، مما يجعل الإنسان يتمثل ويتبنى ويندمج مع خصوصيات وقيم هذا المجتمـع، ومن مقتضيات الانتمـاء أن يفتخر الفرد بـالوطن والدفاع 
حوليتّكليت اللغت العربيت بايتاي البارود (العدد الثالث والثلاثون)

عنه والحرص على سلامته، فالمواطن المنتمي لأسرته ووطنه ودينه وتعدد هذه بإيتاي بارود الانتمـاءات لا يعني تعارضـها بـل هـي منسـمة مـع بعضـها وبعزز البعض

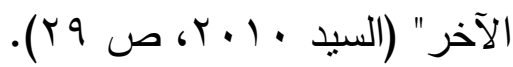

وبُعـرف بأنـه ارتبـاط وانتسـاب الفـرد أو الجماعـة بقطعـةٍ معينـة مـن

الأرض والتعلق بها، وحب أهلها وأصحابها والحنين إليها عند الاغتراب عنها والاستعداد للدفاع عنها من الأخطار، التي تهدد كيانها والانتماء للوطن بتطلب التضحية والنصرة والبذل والعطاء من أجله والولاء والانتماء الوطني لا يرتبط بالالتصاق الجسدي للفرد بالوطن بل يتعدى ذلك، ويجبُ إن بسعى إلى رقي وطنه وخدمته في الداخل والخارج (اقصبعة، م . . ب). وبعرف الباحثين الانتماء الوطني بأنه: شعور داخلي للفرد بأنه عضو فاعل في مجتمعه، وأنه جزء لا يتجزأ عن وطنه، يفديه بروحه ودمهه، ويحافظ على ممتلكاته، ويتمنل هذا الانتماء من خلال الثعور بالمسؤولية الوطنية تجاه المجتمـع، والانتهـاء الـوطني، والالتـزام بمعـايير المجتمـع وقيمـه ( العنـاتي،

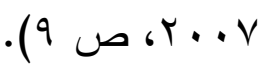

من هنـا برى الباحثون أنـه يتعين على جميع أفراد المجتمع الحفاظ على الوحدة الأولى واللبنة الأساسية التي يتشكل منها الفرد وهي الأسرة كونها ثشكل المدرسة الأولى التي يتعلم فيها الطالب الانتماء الوطني وتعزيز الهوية الوطنية وبتعمق بداخله مما ينعكس على سلوكه في خارج المنزل وبين الأقران. ويـرى الباحثون أن مـن الأهميـة غرس قيم الولاء والانتمـاء للوطن في نفوس الطلاب بالتتوبع بالأنشطة الصفية واللاصفية، وتعزيز مظاهر السلوك المطلوبـة بالعزيمـة والطموح لتتمو هذه القيم ومظاهر السـوك الوطني، وتنشأ في وسط بيئي ينتمي إليه بكل محبة وعشق وعطاء وبكل ما أودعه فيها هذا الوطن الغالي من اعتزاز وفخار من أجل بناء مستقبل مشرق للجميع. 
حوليتة كليت اللغت العربيت بايتاي البارود (العدد الثالث والثلاثون)

ولقد تتاولت العديد مـن الدراسـات المحليـة والعربيـة والأجنبيـة مفـاهيم

الانتمــاء الـوطني وتعزبـز القيم والهوبـة الوطنيـة لـدى الطـلاب في المراحل التعليمية المختلفة، وعلاقتها بدور الأسرة، أو المدرسـة، أو المعلم. فقد هدفت دراسـة الزبـود والخوالدة (V . . r) إلى التعرف على دور معلمي اللغـة العربيـة ومعلمــي "التربيــة الاجتماعيــة والوطنيــة فـي التربيــة الوطنيــة في (المجـال الاجتمـاعي، والمجـال الـوطني، والمجال السباسي) لطلبـتهم مـن وجهة نظر المعلمين أنفسهم في الأردن، تكونت عينة البحث من (79 §) معلماً ومعلمة تم اختيارها بالطريقة العشوائية ، واستخدمت الدراسة استبانة تم إعدادها وتطويرها، وجرى التأكد من صدقها وثباتها. أظهرت نتائج الدراسة أن أعلى دور للمعلمين في تربية الطلبة تربية وطنيـة على المجالات مجتمعة، كان المجال الوطني يليه المجال الاجتماعي ثم المجال السياسي؛ وأن جميع المجالات كانت ذات متوسط حسابي أعلى من ( . . . ). . و أظهرت الدراسة قصوراً في بعض أدوار المعلمين والمعلمات في التربية الوطنية لطلبتهم بحصول العديد من الفقرات التي تمنل أدوار للمعلمين والمعلمات في التربية الوطنية على منتسط حسابي أقل من المستوى المقبول تربوباً، منّل: تعمق وعي الطالب بحلول المشكلات التي يعاني منها المجتمع الأردني، وتنمية روح المسـاءلة لدى الطلبة وتتمية روح تقبل النقد والنقد الذاتي لدى الطلبة. هدفت دراسة الزيادات (1 . . r) إلى التعرف على فاعلية برنامج تعليمي مقترح في اكتساب طلبة الصف العاشر الأساسي للمفاهيم الوطنية في مبحث التربية الوطنيـة والمدنيـة في الأردن، استخدم الباحـث المـنهج شبه التجربي، واختبـار تحصـيلي مكـون مـن ( • ع) فقرة لقيـاس اكتسـاب الطلبـة للمفـاهيم الوطنيـة. وتكونــت عينـة الدراسـة مسن (IM) (I) طالـٍ وطالبـة قسـموا إلـى مجموعتين: تجربيية (VT)، وضابطة ( • V)، حيث تم تطبيق البرنامج التعليمي في (Y ( ) حصـة دراسـية، أظهرت نتـائج الدراسـة فاعليـة البرنـامج التعليمي 
حوليتة كليت اللغت العربيت بايتاي البارود (العدد الثالث والثلاثون)

مقارنة بالبرنامج الاعتيادي في تعزبز المفاهيم الوطنية لدى طلاب المجموعة التجريبية.

أجـرى الثــعراوي ( ( . . ب) دراسـة هـدفت التعـرف إلـى أثـر برنـامج

بالوسـائط المتعددة على تعزبز قيم مفاهيم وقيم الانتماء الوطني لدى طلاب الصف التاسـع في محافظات غزة. وقد استخدم المنهج البنائي لبنـاء برنـامج بالوسـائط المتعددة، فيما استخدم المنهج شبه التجريبي لمعرفة تأثنر البرنامج علي عينـة مكونـة من ( •0) طالبا تم تقسيمها إلى مجموعة تجريبيـة وأخرى ضـابطة وأعد أداتين: الأداة الأولى: مقياس تحصسيلي مكون مـن (Yr) فقرة تغطي جميع القيم والوعي البيئي. والأداة الثانية: مقياس اتجاه لقياس الانتماء الوطني. أظهرت نتائج الدراسـة وجود فروق ذات دلالة إحصـائية بين منوسط درجـات طلبـة المجموعـة التجريبيـة ودرجـات المجموعـة الضـابطة في مقيـاس المفـاهيم والقيم الوطنيـة يعزى للبرنـامج المقترح. ووجود أثر لبرنـامج الوسـائط المتعـددة في تعزبـز قيم الانتهـاء الـوطني لـدى طـلاب الصـف التاسـع في

محافظات غزة.

هدفت دراسة بيترسون وكنوبلز (Peterson \& Knawels 2009) إلى الكثف عن مستوى تحقيق ذلك، واستخدمت الدراسة المنهج الوصفي، وطبقت أداة الاسنبانة على عينة من الطلاب المعلمين في مؤسسات إعداد المعلم في انجلترا، بلغت ( 9 ؟ () طالب معلم بدرسون في (Y Y) مؤسسة لإعداد المعلم، وتوصـلت الدراسـة إلـى مجموعـة مـن النتائج أهمهـا أن الطـلاب المعلمين لا لا يدركون مفهوم المواطنة النشطة أو الفعالة، وأن الأنشطة المتصلة بالمواطنة النشطة لها دورٌ مهٌٌُ في توفير العديد من الأنشطة التربوية في داخل المجتمع المدرسي. وأوصت الدراسة بتطوبر المناهج الدراسية بحيث تشتمل على الحوار ومناقثـة القضـايا المرتبطة بالمواطنة النشطة، وتحقيق الإعداد الفعال للمعلم

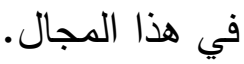


حوليتّكليت اللغت العربيت بايتاي البارود (العدد الثالث والثلاثون)

أجرى المالكي (9 . . ب) دراسـة بهدف التعرف إلى دور التربية الوطنية

في تتمية قيم المواطنة لدى طلبة المرحلة الابتدائية بمحافظة الليث، وتحقيق أهداف التربية الوطنية بالتدريس، والتعرف إلى مدى توافر القيم الوطنية بتلك المقررات، والتعـرف إلىى دور المعلم في غرس القيم الوطنيـة وتتميتهـا لدى الطلبـة، والتعرف إلى إسـهامات نلك المقررات في تعديل سـوك الطلبـة. وقد استخدم المنهج الوصفي وصدم استبانة لهذا الغرض، وتم توزبعها على مجتمع الدراسة المكون من جميع المعلمين الذين يقومون بتدريس مادة التربية الوطنية في المرحلة الابتذائية بمحافظة الليث وعددهم (م0) معلماً. . وقد أظهرت نتائج الدراسـة: الموافقة على مدى تحقيق أهداف مـادة التربية الوطنية بتدربسها في المرحلـة الابتدائيـة الـواردة في أداة هـذه الدراسـة كانــت بدرجـة (متوسـطة). والموافقة على مدى نوفر القيم الوطنية في مقررات التربية الوطنية في المرحلة الابتدائية الواردة في أداة هذه الدراسة كانت بدرجة (كبيرة). والموافقة على دور معلم التربيـة الوطنيـة في غـرس القيم الوطنيـة وتتميتهـا لـدى طلبـة المرحلـة الابتدائية الواردة في أداة هذه الدراسة كانت بدرجة (كبيرة). والموافقة على مدى إسهام مقررات التربية الوطنية في تعديل سلوك طلبة المرحلة الابتذائية إيجابياً الواردة في أداة هذه الدراسة كانت بدرجة (متوسطة). وفي دراسـة العتيـي (11 ( ب) التي هـدفت إلىى الوقـوف على أهـم الأسـاليب التربوبـة لتفعيـل الانتمـاء الـوطني لـدى تلاميذ المرحلـة الابتدائيـة، وتحديد أهم المعوقات التي تحد من دور المدارس الابتدائية في تفعيل الانتماء الوطني لدى تلاميذها، وقد استخدم المنهج الوصفي التحليلي، وتمثلت أدوات البحث في اسـتبانة كأداة لجمـع البيانـات مـن عينـة الدراسـة التي بلـن عددها

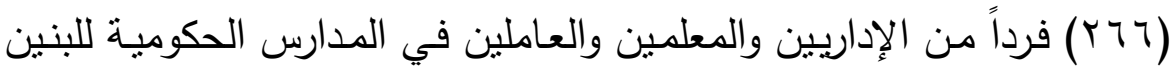
بمدينة الرياض. وكانت أهم النتائج أن أهم الأسـاليب التربويـة المتبعة لتفعيل الانتهـاء الـوطني (الاسـتفادة مـن مجـالس الآبـاء والمعلمـين، وعقد الندوات 
حوليتة كليت اللغت العربيت بايتاي البارود (العدد الثالث والثلاثون)

والمحاضرات التي ترسخ الانتماء في نفوس الطلاب، والتأكيد على أهمبة دور الجماعات المدرسية، وطبع الكتيبات والمطوبات التي تعزز المفاهيم الوطنية وترسيخها في نفوس الطلاب، وتوظيف بعض من حصص النشاط المدرسي لترسيخ مفهوم الانتمـاء الـوطني)، وكانت أهـ المعوقات التي تحد مـن دور المدرسـة الابتدائيـة في تفعيـل الانتمـاء الـوطني عدم تفريـغ المعلم وانشـغاله بالأعباء المدرسية، وضعف الموارد المالية في المدرسـة التي تساعد على دعم البرامج الخاصة بتفعيل قيم المواطنة. وهدفت دراسـة عيد (Eid 2015) التي بحثت في المواطنة، والمجتمـع والهوبـة الوطنبـة، وتصـورات الثـباب في البيئة البحربنيـة" ليكونـوا مـواطنين مشـاركين بفاعلية، وقدمت الدراسـة الخلفية النظريسة والإدراكية لمقياس إذا كان الطـلاب قـد زودوا بالمعرفـة المدنيـة وبـالفهم الضـروري للمشـاركة بفعاليـة كمـواطنين، وتزوبـد الطـلاب بمفـاهيم عـن المواطنـة وعـن الهوبـة والاهنمـام بموضـوعات المجتمـع. واستخدمت الدراسـة البيانـات النوعيـة والكميـة من أجلـ تحليل الأسـاليب التي يدرك الطـلاب بها هويتهم ومـواطنتهم، وتم اسـتخدام

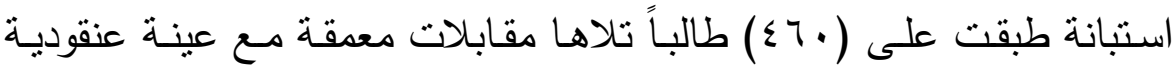
مكونة من (Yr) طالباً. وبينت النتائج التي تم التوصل إليها المفاهيم المهمة لمشكلات يواجهها الطلاب في أثناء مشاركتهم في عملية التعلم عن المواطنة، مدا يسـاعد التربوبين، ومصدمي المناهج وصناع القرار في البناء على تلك المفاهيم، من أجل فهم المحتوى وتتقيحه وأنواع النشاطات التي بجب أن تقدم من أجل تحقيق التعلم الفاعل. وفي دراسـة المزيـود (0) ـ ب) التي هدفت التعـرف إلى تعزيـز الانتمـاء للوطن، ودور الأبعاد الثخصية للمعلم في تتمية الانتماء للوطن والتعرف إلى أهمية التربية بالمواطنة في صياغة المعلم لأهدافه في المقررات الدراسية وأثرها في تعزيز الانتماء للوطن، وقد اتبع المنهج الوصفي التحليلي، وقد توصل إلى 
حوليتة كليت اللغت العربيت بايتاي البارود (العدد الثالث والثلاثون)

أنه يجب على المعلم أن بهتم بتطوير أربعة جوانب تعزز الانتماء الوطني لدى بإيتاي الطالب، وهـي: المعرفـة، والقيم والميـول والاتجاهـات الوجدانيـة، والمهـارات والمشاركة الاجتماعية، وذللك بتضمينها في الأهداف السلوكية التي يصوغها المعلم عند إعداد الدروس اليوميـة للمقررات الدراسـية، ويراعي في تتفيـها مقيـاس الأسـاليب والطرائق التدربسية المناسـبة. وإن واقـع المقررات الدراسـية وغيرهـا ودورهـا في تتميـة روح المواطنـة لـدى الطـلاب وجدناها تفتقد إلـى المقومات الأساسية، التي لا بد للقائمين عليها، من إعادة صياغتها لتتواكب متطلبات التغيرات المحلية والعالمية.

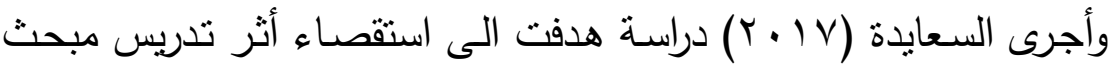
التزبية الوطنية وفق برنامج تعليمي في اكتساب مفاهيم الانتماء الوطني لدى طـلاب الصـف العاثـر الأساسـي في الأردن، اتبعــت الدراسـة المـنهج شـبه التجريبي، وتكونت عينة الدراسـة من (TV) طالباً من طلاب الصف العاثر من مدارس مديريـة التربية والتعليم في محافظة البلقاء (قصبة السلط)، وتم اختيارهم بالطريقة القصدية، وتم استخدام التعبين العشوائي لتوزبع أفراد الدراسـة إلى مجموعتين: المجموعة التجريبية وعدد أفرادها (هب) طالباً، درسـت وفق البرنـامج التعليمس، والمجموعـة الضـابطة وعدد أفرادهـا (Yr) طالبـاً درســ باسـتخدام الطربقة الاعتياديـة، وتـم إعـداد مقيـاس مفـاهيم الانتمـاء الـوطني. أظهرت نتـائج الدراسـة أثر البرنـامج التعليمسي في اكتسـاب مفـاهيم الانتمـاء الوطني لاى طلاب الصف العاشر الأساسي في الأردن. التعقيب على الدراسات السابقة: بعد عرض الدراسـات السابقة المتعلقة بمفاهيم الانتمـاء الوطني وممارسـة السلوك الديمقراطي: - تتاولت العديـد مـن الدراسـات إمكانيـة اكتسـاب مفـاهيم الانتمـاء الـوطني وتعزيز الهوية الوطنية لدى الطلاب، ، من مثل دراسات( الزبود والخوالدة 
مدى تركيز معلمي اللغت العربيت على القيم والهويت الوطنيت وتعزيزها لدى طلاب المرحلت

المتوسطت بمحافظت رنيت القيب والهويت الوطيتي

حوليتّكليت اللغت العربيت بايتاي البارود (العدد الثالث والثلاثون)

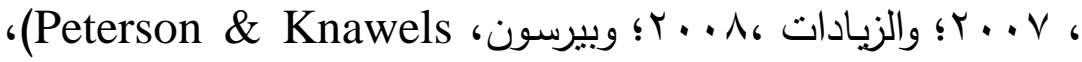

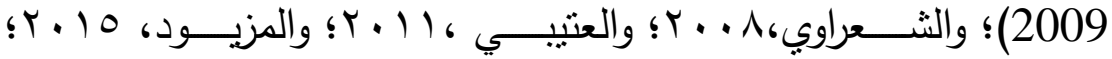

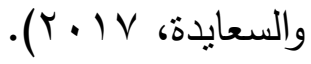

- - اتبعـت الدراسـات منـاهج بحـث مختلفـة منهـا المـنهج الوصـفي التحليلي

ومنهج شبه التجريبي في دراسة قيم الانتماء الوطني والهوية الوطنية.

- تتثابه الدراسة الحالية مع بعض الدراسات السابقة في تتاولها مدى تركيز معلمي اللغــة العربيـة على القيم والهويـة الوطنيـة وتعزيزهـا لـدى طـلاب المرحلـة المتوسـة بمحافظـة رنيـة بالمملكـة العربيـة السـعودية مـن مثنل فئل

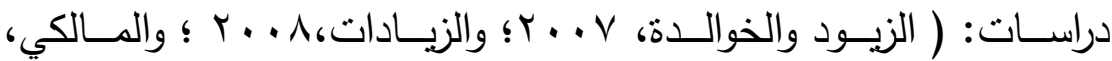

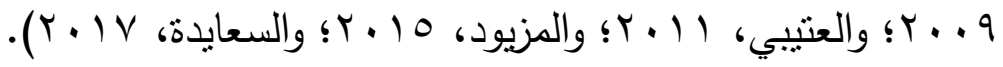
- استفاد الباحثون من الدراسات السابقة في التعرف إلى بناء أدوات الدراسة الحالية والاطلاع على الأدب النظري، وكيفية تطبيق هذه الأدوات وتفسير لته

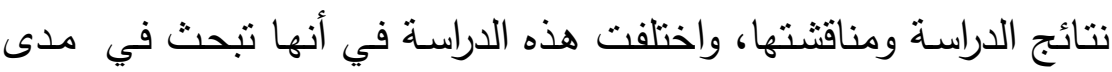
تركيز معلمي اللغة العربية على القيم والهوية الوطنية وتعزيزها لدى طلاب المرحلة المتوسطة بمحافظة رنية بالمملكة العربية السعودية، لقلة الدراسات في هذا المجال على المستوى المحلي في - حدود إطلاع الباحث- مما يجعل هذه الدراسة إضافةً إلى ميدان البحث التربوي. مشكلة الاراسة وأسئلتها:

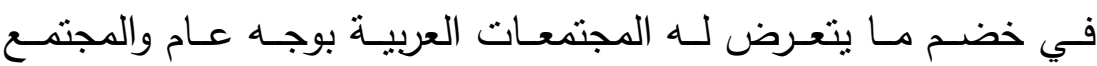
السعودي خاصة من مخاطر جمة، نتيجة المؤثرات الداخلية والخارجية وفي لري ظل التغيرات الاجتماعية والتقافية يمر بها الوطن العربي بوجه عام، ونتيجة لما صاحب التكنولوجيا الحديثة وثورة الاتصالات، ومع تغلغل وسائل التواصل على نظامنا الاجتماعي وما أفرزته من سلبيات تهدد بفقدان قيم الولاء والهوية

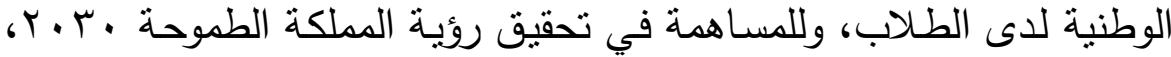


مدى تركيز معلمي اللغت العربيت على القيم والهويت الوطنيت وتعزيزها لدى طلاب المرحلت

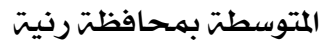

حوليتّكليت اللغت العربيت بايتاي البارود (العدد الثالث والثلاثون)

تبرز أهمية الدور الذي يمكن أن تؤديه المؤسسة التعليمية المتمنلة بالمدرسية بما بيوافر فيها من موارد وإمكانات مؤسسية تعليمية وتربوبة تمكنها من حثد

وتوجيه الطلاب نحو القيم الوطنية المرغوبة اجتماعياً بما تتضمنه من ولاء للوطن والتزام بمعايير المجتمع، وشعور بالمسؤولية الأخلاقية تجاه ما يواجهوا من قضنابا - من

وبالتالي، جاءت هذه الدراسـة للتعرف على مدى تركيز معلمي اللغة العربية على القيم والهوية الوطنية وتعزيزها لدى طلاب المرحلة المتوسطة بمحافظة رنية بالمملكة العربية السعودية. ومن ثم تحديد مشكلة الدراسة في السؤال التالي: ما مدى تركيز معلمي اللغة العربية على القيم والهويـة الوطنية وتعزيزها لاى طلاب المرحلة المتوسطة بمحافظة رنية بالمملكة العربية السعودية "؟ وينبثق عن هذا السؤال الأسئلة الفرعية الآتية: 1- مـا مـدى تركيز معلمي اللغــة العربيـة على الانتمـاء الـوطني والهويسة

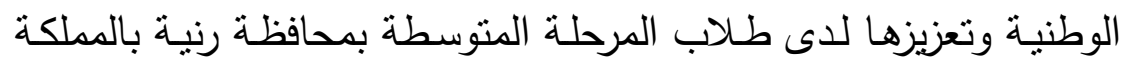

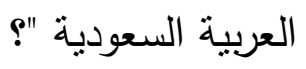

ץ- مـا مدى نركيز معلمي اللغـة العربية على قيم الالتزام بمعايير المجتمـع وتعزيزهـا لدى طـلاب المرحلة المتوسطة بمحافظـة رنيـة بالمملكة العربيـة

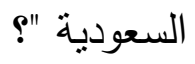

r- ما مدى تركيز معلمي اللغة العربية على مفاهيم المسؤولية الوطنية تجاه المجتمع وتعزيزها لدى طلاب المرحلة المتوسطة بمحافظة رنية بالمملكة

$$
\text { أهداف الدراسية: السعودية "؟ }
$$

هدفت الدراسـة إلى تحديـد مدى تركيز معلمي اللغـة العربيـة على القيم والهويـة الوطنيـة وتعزيزهـا لـدى طـلاب المرحلـة المتوسـطة بمحافظــة رنيـة 
مدى تركيز معلمي اللغت العربيت على القيم والهويت الوطنيت وتعزيزها لدى طلاب المرحلت

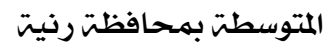

حوليتة كليتتا اللغت العربيت بإيتاي البارود (العدد الثالث والثلاثون)

بالمملكة العربية السعودية، من خـلال التعرف على مدى نركيزهم على قيم الالتزام بمعـايير المجتمـع وتعزيزهـا، وقيم الالتزام بمعـايير المجتمـع وتعزيزهـا، والمسـؤولية الوطنيـة تجـاه المجتمـع وتعزيزهــا لـدى طلبـة المرحلـة المتوســة بمحافظة رنية بالمملكة العربية السعودية. أهمبة الدراسةة:

1- تعد هذه الدراسـة محاولة إجرائية يتوقع أن تساعد نتائجها القائمين على العمليـة التعليميـة في مكتب التعليم بمحافظة رنيـة بالمملكة العربيـة السعودية وربما غيرها من إدارات التعليم بالمحافظات السعودية الأخرى وصانعي السياسة التعليمية، ومتخذي القرار التعليمي والتربوي في تحديد الأساليب المنلى لتفعيل دور المعلمين في تتمية قيم المواطنة والهوية الوطنية لدى الطلبة.

r- مساعدة معلمي اللغة العربية على تطوير دورهم في التركيز على تعزيز القيم والهويـة الوطنية لدى الطلاب . وبالتالي تتحقق أقصى فائدة للعملية التعليمية، وبسهم ذلك في تحقيق رؤية المملكة ، ب . ب. ب- يُتوقع أن تمثل إضـافة مهمة للمكتبة العربية واستثارة لطلاب البحث. العلمي والمهتمين بإجراء المزبد من الدراسات في هذا المجال الحيوي والوطني المهم. حدود الدراسةة:

حدود موضوعية: مدى تركيز معلمي اللغة العربية على القيم والهوبة الوطنبة وتعزيزهـا لـدى طلبـة المرحلـة المتوسـطة بمحافظلة رنبـة بالمملكـة العربيـة السعودية. هـود بشـربـة: معلمو اللغـة العربيـة في المـدارس المتوسطة بمحافظـة رنيـة بالمملكة العربية السعودية. 
مدى تركيز معلمي اللغت العربيت على القيم والهويت الوطنيت وتعزيزها لدى طلاب المرحلت

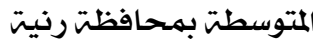

حوليتة كليت اللغت العربيت بايتاي البارود (العدد الثالث والثلاثون)

حدود مكانية: المدارس المتوسطة للذكور التابعة لمكتب التعليم بمحافظة رنية

بالمملكة العربية السعودية.

حـدود زمانيـةة: طبقت الدراسـة في الفصـل الدراسـي الأول للعـام الدراسـي

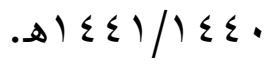

مصطلحاث الدراسة:

القيمـة لغـة: تعددت المعـاني اللغويـة للقيمـة، فقد جـاء في مختار الصـحاح للرازي: "قام" المتاع بكذا، أي: تعدلت قيمته، به و "القيمة" الثمن الذي يقاوم به المتاع، أي: يقوم مقامه، والجمع" القيم" ( الرازي، 990 ( ، DVV). القيم: مجموعة من التصورات والمفاهيم التي تكون إطاراً للمعايير والأحكام والمثل والمعتقدات والتفضيلات التي تتكون لدى الفرد من خلال تفاعله مـع المواقف والخبـرات الفرديـة والاجتماعبـة، بحيــث تمكنـه مسن اختيـار أهـداف وتوجهات لحياته ويراها جديرة بتوظيف إمكانياته وتتجسد من خلال الاهتمامات أو الاتجاهات أو السلوك العملي أو اللفظي بطريقة مباشرة وغير مباشرة (أبو

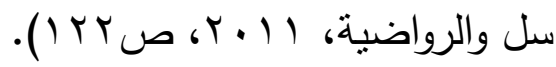

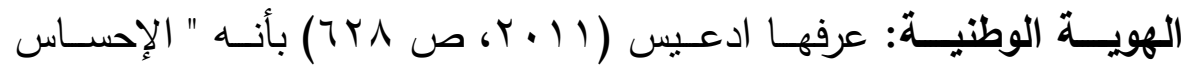
بالارتباط بـالأرض التي ولد فيها وتوحد معها، ويثـعر بأن هنالك رابطاً بينه وبينها كالدم والمصير والأهداف والثقافة والتاريخ والأمان، وبدافع عنها إذا ما تعرضت هذه الرابطة إلى اعتداء أو مصادرة". ويعرف في هذه الدراسة إجرائياً: شعور داخلي للفرد بأنه عضو فاعل في مجتمعه، وأنه جزء لا يتجزأ عن وطنه، يفديه بروحه ودمـه، وبحافظ على ممنلكاته ويعبـر عنهـا بالدرجـة التي حصـل عليهـا الطالب باختبـار مفـاهيم الانتماء الوطني الذي أعد لهذا الغرض. تعزيز الهويـة الوطنبـة: وبعرف في هذه الدراسـة إجرائياً: السلوك المعبر عن اكتسـاب الفـرد لمفاهيم الانتمـاء الوطني والهوبـة الوطنيـة المنتلـة في المفاهيم 
حوليتّكليت اللغت العربيت بايتاي البارود (العدد الثالث والثلاثون)

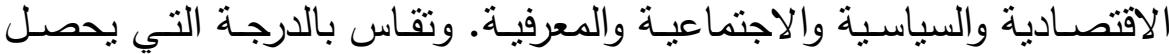
عليها المستجيب على فقرات أداة الدراسة المعدة لهذا الغرض. معــم اللغـة العربيـة: الثـخص الذي يحمل مـؤهلاً في اللغـة العربيـة شهـادة البكالوريوس كحد أدنى، ويقوم بتدريس مبحث اللغـة العربية لطلاب المرحلة

المتوسطة (قانون وزارة التعليم، رقم ب لسنة ع9 9 ( ). المرحلة المتوسطة: هي المرحلة الثانية من مراحل التعليم العام ونتتمل على الصفوف الثناث من الأول المتوسط إلى الثالث متوسط.

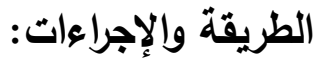
منهج الدراسة: اعتمدت الدراسة المنهج الوصفي الذي يعتمد على دراسة الواقع ويهتم

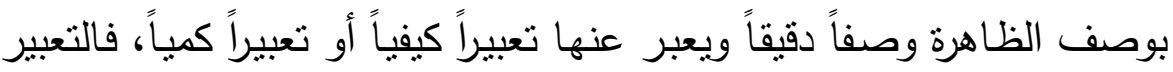
الكيفي يصف لنـا الظـاهرة ويوضـح خصائصـها، أمـا التعبير الكمي فيعطينـا وصفاً رقمياً يوضح مقدارها أو حجمها ودرجات ارتباطها مع الظواهر المختلفة وئة

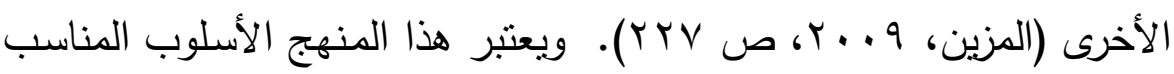
في دراسـات العلـوم الإنسـانية بصـورة عامـة، والتربويسة والاجتماعيـة بشـكل خاص، لاعتماده على وصف ما هو كائن وتقسيره.

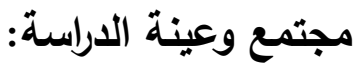

تكونـت عينـة الدراسـة مـن جميع معلمـي اللغــة العربيـة في المـدارس

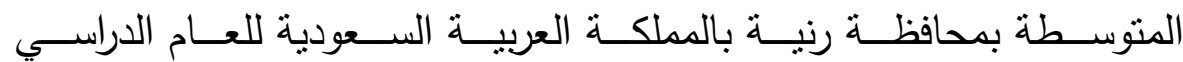

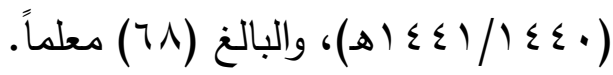

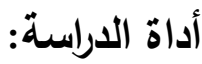

بعد مراجعة الإطار النظري، والدراسات السابقة تم تصميم الأداة بما يتناسب مع الغرض من الدراسـة ويحقق أهدافها، وقد اشتملت الاستبانة في صورتها النهائية على (Y) عبارة تصف درجة تركيز معلمي اللغة العربية 
حوليتة كليت اللغت العربيت بايتاي البارود (العدد الثالث والثلاثون)

على القيم والهوبـة الوطنيـة ( مرتفعـة جـداً، مرتفعـة، منوسـطة، منخفضـة، منخفضـة جداً)، لتصف ثنلاثة أبعاد تمنثل قيماً وطنية رئيسة لتعزيز الهوبة

الوطنبة لدى طلاب المرحلة المتوسطة، (الانتماء الوطني والهوبة الوطنية: اشتمل على (V) عبارات، الالتزام بمعابير وقيم المجتمع: تضمن (V) عبارات، المسؤولية الوطنية تجـاه المجتمـع: واشتمل على (V) عبارات). ولتقدير استجابات أفراد عينة الدراسة على الأداة تم اعتماد مقياس ليكرت الخماسي (1-0) على التوالي، وحدد طول الفئة بالمعادلة الآتية: القيمة العليا- القيمـة الدنيا / عدد المستوبات= (0-1 / 3 / 1.33 ) ) ووفقاً لهذه المعادلة تم تحديد مستوبات المتوسطات كا يلي: مستوى متدن من (1- 2.33)، ومستوى متوسط من (2.34 -3.66) ومستوى مرتفع من (3.67 - 5.00).

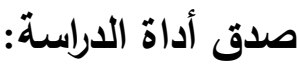
للتحقق من صدق أداة الدراسة تم اعتماد طريقة صدق المحتوى، وتم عرض الأداة على (7) محكمين من أسـاتذة الجامعات السعودية المتخصصين في مناهج وطرق تدريس اللغة العربية لتعرف درجة ملاعمـة الفقرات للأبعاد التي تضمنتها، ووضوحها اللغوي، وطلب منهم الحكم على كل فقرة، وإجراء التعديل المناسب ، وتم إجراء التعديلات اللزمة على فقرات الاستبانة في ضوء ملاحظات وآراء المحكمين ب- صدق الاتشاق الاخلي للأداة

تم اسـتخراج معـاملات صـدق الاتسـاق الـداخلي باسـتخدام معامـل ارتبـاط بيرسون (Pearson Correlation)، بين كل فقرة من الفقرات مـع الدرجـة الكلية للأداة، لإظهار مدى اتساق الفقرات في قياس مدى تركيز معلمي اللغة العربيـة على تعزبـز الهوبـة الوطنيـة لـدى الطـلاب، وبيـين الجدول (1) قيم معاملات الارتباط لفقرات أداة الدراسة. 
مدى تركيز معلمي اللغت العربيت على القيم والهويت الوطنيت وتعزيزها لدى طلاب المرحلت

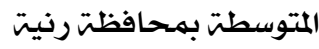

حوليت كليتا اللغت العربيت بإيتاي البارود (العدد الثالث والثلاثون)

الجدول ا: قيم معامالات الارتبـاط لقياس مدى الاتسـاق الداخلي لفقرات أداة

الدراسة مع الدرجة الكلية

\begin{tabular}{|c|c|c|c|c|c|}
\hline الارتباط & رقم الفقرة & الارتباط & رقم الفقرة & الارتباط & رقم \\
\hline **. . $7 V$ & 10 & $* * . .0 \mathrm{~V}$ & $\Lambda$ & $* * . .7 \varepsilon$ & 1 \\
\hline$* * . .00$ & 17 & $* * . .7 \varepsilon$ & 9 & $* * .01$ & r \\
\hline$* * .09$ & 18 & $* * . .0 \wedge$ & 1 . & * & r \\
\hline r**. & 11 & $* * .00$ & 11 & $* * .7 \varepsilon$ & $\varepsilon$ \\
\hline$* * .7 \mathrm{~V}$ & 19 & $* * .01$ & $1 T$ & $* * . .0 Y$ & 0 \\
\hline$* * .79$ & r. & **. . 70 & س & $* * .07$ & 7 \\
\hline$* *$ *. \ᄉ & YI & $* * .7 r$ & $1 \varepsilon$ & $* * .00$ & V \\
\hline
\end{tabular}

* معامل الارتباط دال إحصائيًا عند مستوى الدلالة ( ( +.

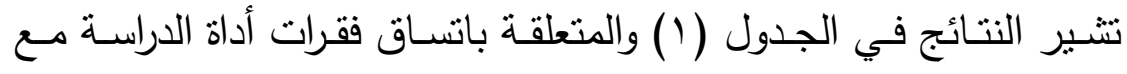

الدرجة الكلية، إلى أن قيم معاملات الارتباط للفقرات مع الدرجة الكلية تراوحت

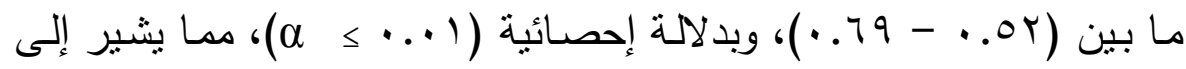

مناسبة هذه الفقرات لقياس مدى نركيز معلمي اللغة العربية على تعزيز الهويـة

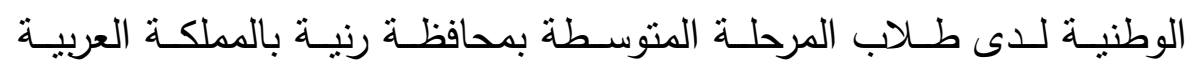

السعودية من وجهة نظر المعلمين أنفسهر.

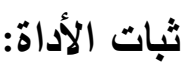

تــم التحقـق مــن ثبــات أداة الدراســة باســتخدام معادلــة كرونبــاخ ألفــا

"Cronbach's alpha" من خلال التطبيق على عينة استطلاعية مشابهة

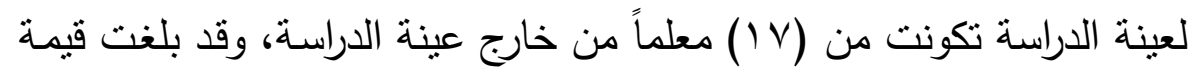

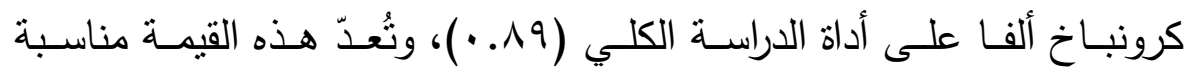

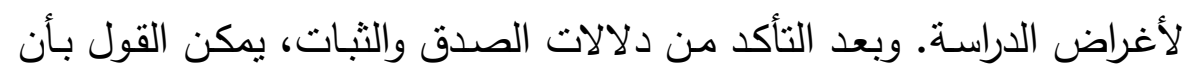


مدى تركيز معلمي اللغت العربيت على القيم والهويت الوطنيت وتعزيزها لدى طلاب المرحلت

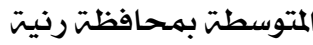

حوليتة كليت اللغت العربيت بايتاي البارود (العدد الثالث والثلاثون)

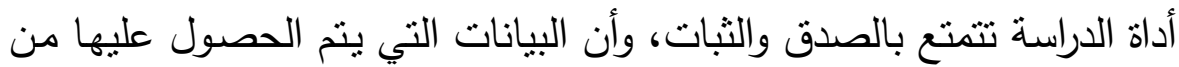
خلال تطبيقها على عينة الدراسة تخضع لدرجة مقبولة من الاعتمادية ويمكن الوثوق بصحتها. والجدول (Y) يبين معاملات الثبات. الجدول (ץ): قيم معاملات الثبات لمجالات الأداة والأداة ككل

\begin{tabular}{|c|c|c|}
\hline الاتساق الاخلي & معامل ارتباط بيرسون & المجال \\
\hline$\cdot . \wedge$ & $.9 r$ & الانتمار الوطني والهوية \\
\hline.$\wedge$ & .94 & الالتزام بمعايير وقيم \\
\hline.$\wedge T$ &. .91 & المسؤولية الوطنية تجاه \\
\hline..$\wedge r$ &. .94 & الكلي \\
\hline
\end{tabular}

يوضح جدول (r) قيم معاملات الارتباط بين التطبيقين على كل مجال من مجالات الأداة، وتراوحت قيم معاملات ثبات مجالات الأداة بين (19. . -

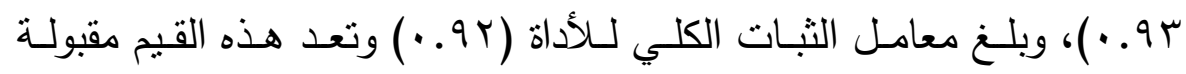
لأغراض الدراسة. المعالجة الإحصائية

ا. المتوسـطات الحسـابية والانحرافـات المعياريـة لإجابـات أفـراد عينـة الدراسة حول أبعاد أداة الدراسة وعباراتها، ورتب العبارات والأبعاد. r. معادلة كرونباخ ألفا "Cronbach's alpha". r. معامل ارتباط بيرسون (Pearson Correlation)، 
مدى تركيز معلمي اللغت العربيت على القيم والهويت الوطنيت وتعزيزها لدى طلاب المرحلت

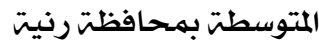

حوليتة كليت اللغت العربيت بايتاي البارود (العدد الثالث والثلاثون)

عرض نتائج الدراسة ومناقشتها:

أولاً: عرض التتائج المتعلقة بالسوأل الرئيس: ما مدى تركيز معلمي اللغة العربيـة على القيم والهويـة الوطنيـة وتعزيزهـا لدى طـلاب المرحلـة المتوسطة بمحافظة رنية بالمملكة العربية السعودية "ب للإجابـة عـن هـذ السـؤال، تـم اسـتخدام حزمـة (SPSS) الإحصـائية باسـتخراج المتوسـات الحسـابية والانحرافـات المعياربـة لمـدى تركيز معلمي اللغــة العربيـة علىى القـيم والهويـة الوطنيـة وتعزيزهـا لـدى طـلاب المرحلـة المتوسطة بمحافظة رنية بالمملكة العربية السعودية على أبعاد الدراسة مجتمعة

$$
\text { (الكلي)، كما هو موضتح في الجدول (ب): }
$$

الجدول (ب): المتوسطات الحسابية والانحرافات المعياريـة لمدى تركيز معلمي اللغــة العربيـة علـى القيم والهوبــة الوطنيـة وتعزيزهـا لـدى طـلاب المرحلـة المتوسطة بمحافظة رنية بالمملكة العربية السعودية على أبعاد الدراسة

\begin{tabular}{|c|c|c|c|c|}
\hline التركيز & الانحراف & المتوسط الحسابي & البعد & الرتبة \\
\hline مرتفعة & זד. . & r.9દ & الانتماء الوطني & 1 \\
\hline مرتفعة &. .01 & $r .19$ & المسؤولية الوطنبة & r \\
\hline مرتفعة & .7. & r.Av & وقبم الالتزام بمعابير & r \\
\hline مرتفعة &. .01 & r. & الابعاد ككل & \\
\hline
\end{tabular}

يتبين من الجدول (ب) أن مدى تركيز معلمي اللغـة العربية على القيم

والهويـة الوطنيـة وتعزيزهـا لـدى طـلاب المرحلـة المتوسـطة بمحافظـة رنيـة بالمملكة العربيـة السـودية على أبعاد الدراسـة (الكلي) "مرتفعاً"، حبـث جـاء 
مدى تركيز معلمي اللغت العربيت على القيم والهويت الوطنيت وتعزيزها لدى طلاب المرحلت

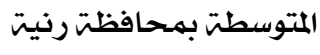

\section{حوليتة كليت اللغت العربيت بايتاي البارود (العدد الثالث والثلاثون)}

الأعلى في التركيز بُعد "الانتماء الوطني والفتهريتية الوطنية الوردية"، يليه بُعد "الالتزام

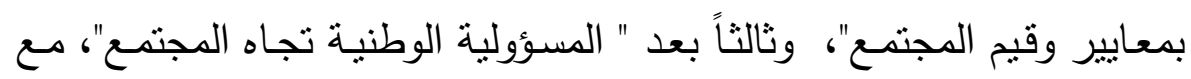
العلم أن جميع الأبعاد كانت ذات متوسط حسابي أعلى من المستوى المقبول

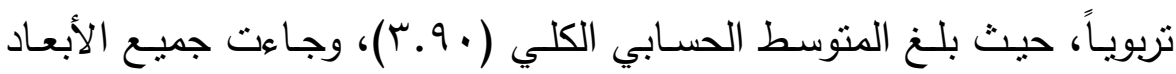
بدرجة مرتفعة من التركيز •

ولمعرفـة مـدى تركيزز معلمـي اللغــة العربيـة على القيم والهويـة الوطنيـة

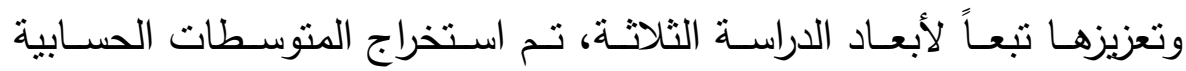

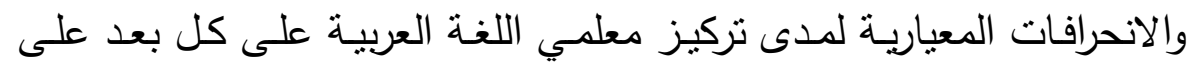
حدة، وذللك على النحو الآتي:

\section{أولاً: بعد الانتماء الوطني والثهوية الوطنية}

الجدول (ع): المتوسطات الحسابية والانحرافات المعيارية لمدى تركيز معلمي اللغة العربية على بعد الانتماء الوطني والهوية الوطنية

\begin{tabular}{|c|c|c|c|c|}
\hline التركيز & الانحراف & الحسابي & الفقرات & الرتبة \\
\hline مرتفعة & זד. & క.1. & تعرفه بأنشطة وفعاليات الطلاب & r \\
\hline مرتفعة &. .01 & $\varepsilon \ldots$ & أعزز مشاعر الولاء & $r$ \\
\hline مرتفعة & .7 & $r .91$ & منشورات أقدم للطلاب & 1 \\
\hline
\end{tabular}


مدى تركيز معلمي اللغت العربيت على القيم والهويت الوطنيت وتعزيزها لدى طلاب المرحلت

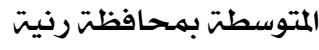

\begin{tabular}{|c|c|c|c|c|}
\hline & & & قيمة المواطنة & \\
\hline مرتفعة &. .01 & r.90 & قبر أثرك الطلاب في & $\varepsilon$ \\
\hline مرتفعة & r & r.q. & أثرك الطلاب & V \\
\hline مرتفعة & .01 & r.یᄉ & ألعزز روح الاحترام المواطن والامتياز لحقوت & 0 \\
\hline مرتفعة & .7. & r.vo & أعزز روح الاعتزاز & $\varepsilon$ \\
\hline مرتفعة & .01 & r.q & الكلي & \\
\hline
\end{tabular}

يظهر مـن الجدول (ع) أن المتوسطات الحسـابية لتقديرات أفراد العينـة

لمدى تركيز معلمي اللغة العربية على عبارات بعد "الانتمـاء الوطني والهويـة

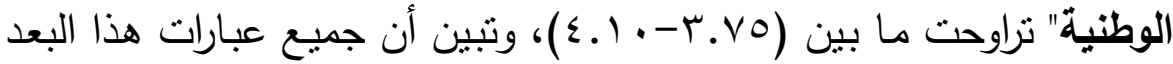
جـاءت بدرجـة نركيز "مرتفعـة" مـن قبـل معلمي اللغـة العربيـة، حيـث جـاءت 
مدى تركيز معلمي اللغت العربيت على القيم والهويت الوطنيت وتعزيزها لدى طلاب المرحلت

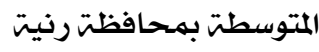

حوليت كليتة اللغت العربيت بإيتاي البارود (العدد الثالث والثلاثون)

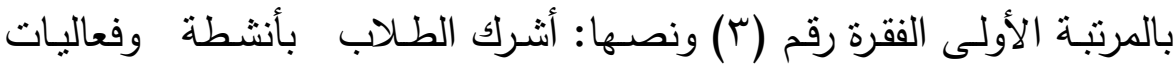
تعرفهم بالمؤسسات الوطنية، بمنوسط حسابي ( • . ؟) وبدرجة تركيز مرتفعة، بينمـا جـاءت بالمرتبـة الأخيـرة الفقـرة رقم (ع) ونصـها: أعـزز روح الاعتزاز بالوطن وبالأمة العربية لدى الطلاب، بمتوسط حسابي (م. (r) وبدرجة تركيز

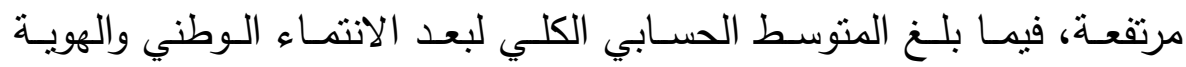
الوطنية (؟ و.ب) وبدرجة تركيز مرتفعة. ثانياً: بعد المسؤولية الوطنية تجاه المجتمع الجدول (0): المنتسطات الحسابية والانحرافات المعيارية لمدى تركيز معلمي اللغة العربية على بعد المسؤولية الوطنية تجاه المجتمع

\begin{tabular}{|c|c|c|c|c|}
\hline التركيز & الانحراف & المتوسط & الفقرات & الرتبة \\
\hline مرتفعة & r . & $\varepsilon .$. & روحز المحزف لافظة علاب & 1. \\
\hline مرتفعة & .01 & $\varepsilon \ldots$ & أعزز روح الاحترام & $1 \varepsilon$ \\
\hline مرتفعة & .7. & r.9V & 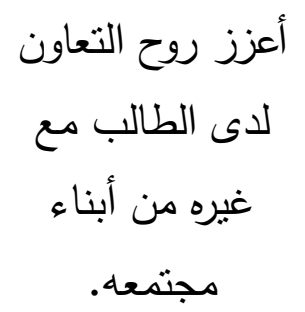 & $1 T$ \\
\hline مرتفعة &. .01 & r. & أوضح أهمبة قيام & $\Lambda$ \\
\hline
\end{tabular}


مدى تركيز معلمي اللغت العربيت على القيم والهويت الوطنيت وتعزيزها لدى طلاب المرحلت

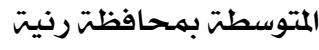

\begin{tabular}{|c|c|c|c|c|}
\hline \multicolumn{5}{|c|}{ حوليتش كليت اللغتت العربيتت بإيتاي البارود (العدد الثالث والثلاثون) } \\
\hline & & & المجتمع على أكمل & \\
\hline مرتفعة & זד. & r.人o & قركز على ضرورة & r \\
\hline مرتفعة & .01 & r.A. & أعزز لدى الطلاب & 9 \\
\hline مرتفعة & .7. & •. & للمشاركة في خدمة المجلاب & 11 \\
\hline مرتفعة & .01 & r.یq & الكلي & \\
\hline
\end{tabular}

يظهر مـن الجدول (0) أن المتوسطات الحسـابية لتقديرات أفراد العينـة

لمدى تركيز معلمي اللغة العربية على عبارات بعد " المسؤولية الوطنية تجاه

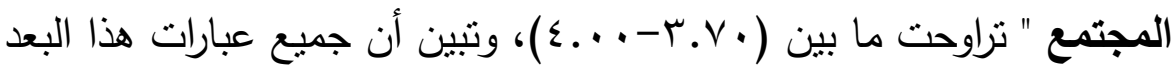

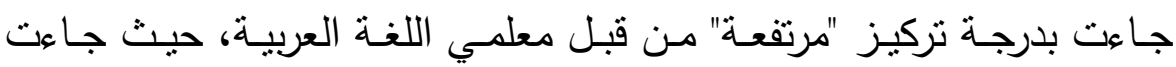

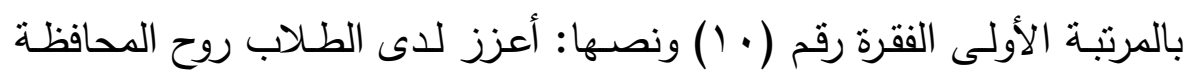
على وحدة المجتمع، بمتوسط حسابي ( . .ـ؛) وبدرجة تركيز مرتفعـة، بينما

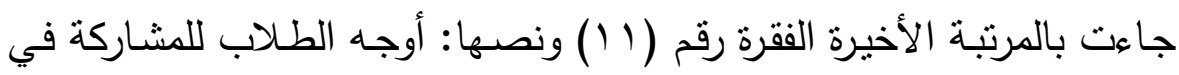
خدمة المجتمع المحلي، بمتوسط حسابي (• •.V) وبدرجة تركيز مرتفعة، فيما

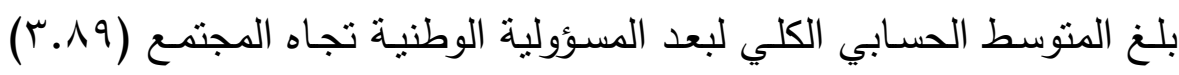
وبدرجة تركيز مرتفعة. 
مدى تركيز معلمي اللغت العربيت على القيه والهويت الوطنيت وتعزيزها لدى طلاب المرحلتة المتوسطت بمحافظت رنيتر

حوليتّ كليت اللغت العربيت بإيتاي البارود (العدد الثالث والثلاثون)

ثالثاً: بعد الالتزام بمعاييز وقيم المجتمع

الجدول (7): المتوسطات الحسابية والانحرافات المعياربة لمدى نركيز معلمي

اللغة العربية على بعد الالتزام بمعابير وقيم المجتمع

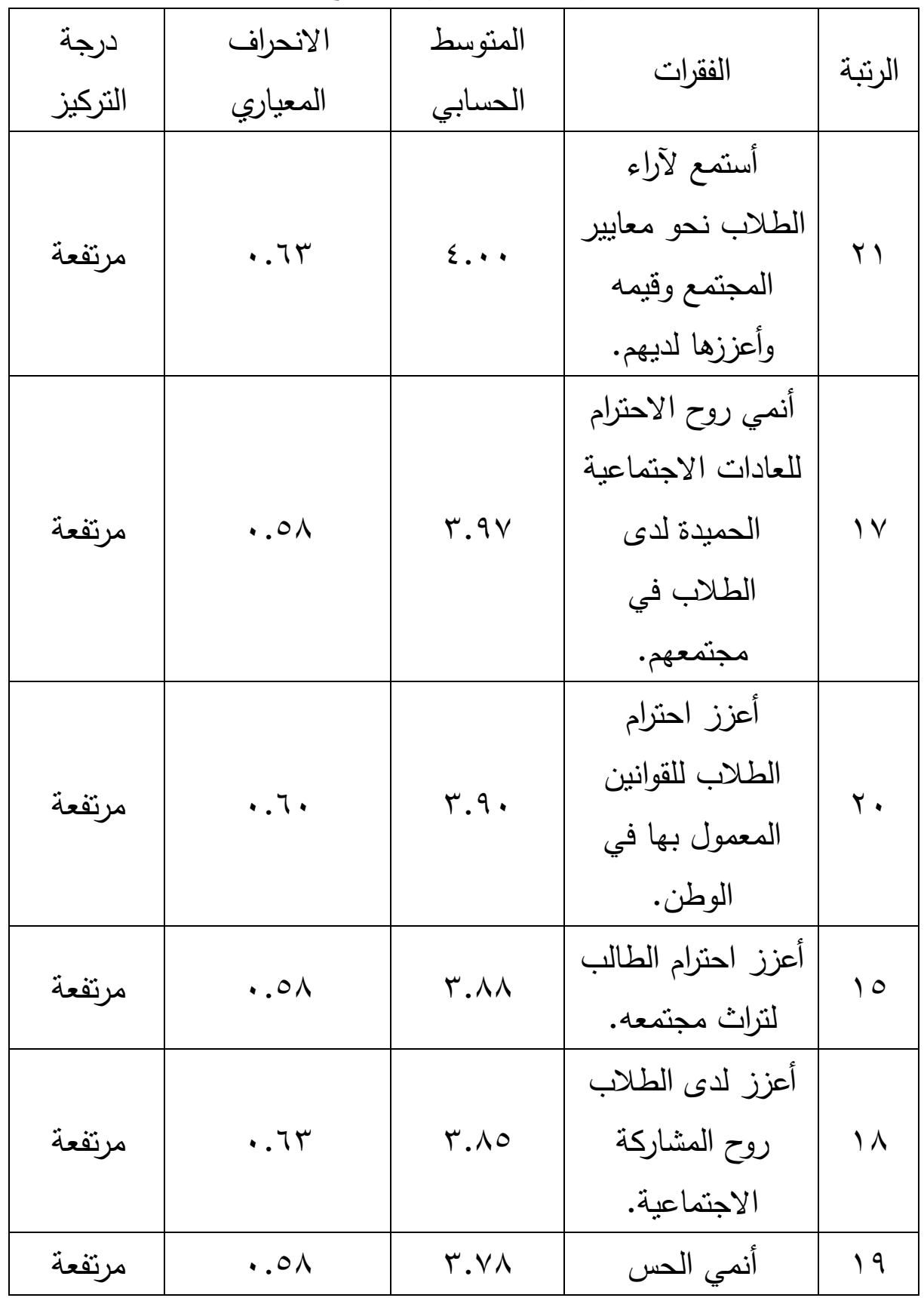

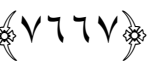


مدى تركيز معلمي اللغت العربيت على القيم والهويت الوطنيت وتعزيزها لدى طلاب المرحلت

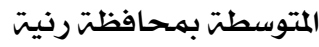

\begin{tabular}{|c|c|c|c|c|}
\hline \multicolumn{5}{|c|}{ حوليتّ كليت اللغت العربيتت بإيتاي البارود (العدد الثالث والثلاثون) } \\
\hline & & & بالمسؤولية الوطنية & \\
\hline مرتفعة & .7. & r.VY & تعليمية تعزز للطلاب أنشطة & 17 \\
\hline مرتفعة & .01 & r.AV & الكلي & \\
\hline
\end{tabular}

يظهر مـن الجدول (T) أن المتوسطات الحسـابية لتقديرات أفراد العينـة

لمدى نركيز معلمي اللغـة العربية على عبارات بعد " الالتزام بمعايير وقيم

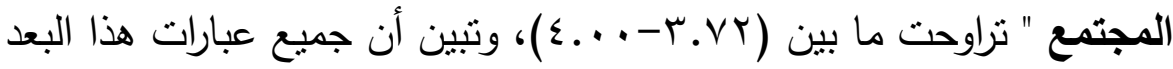
جـاءت بدرجـة تركيز "مرتفعـة" مـن قبـل معلمسي اللغــة العربيـة، حيـث جـاءت

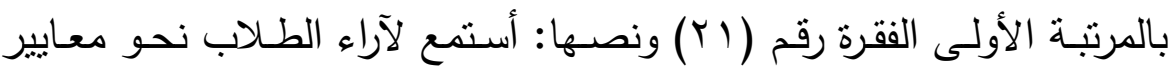

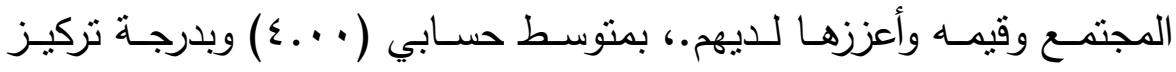
مرتفعة، بينما جاءت بالمرتبـة الأخيرة الفقرة رقم (7 ( ) ونصها: أقدم للطلاب

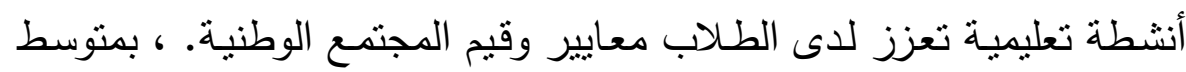
حسابي (Y.VY) وبدرجة تركيز مرتفعة، فيما بلغ المتوسط الحسابي الكلي لبعد الالتزام بمعايير وقيم المجتمع (r.NV) وبدرجة تركيز مرتفعة. مناقشة النتائج وتفسيرها:

وبعد استعراض النتائج التي توصلت إليها الدراسـة تبين أن معلمي اللغـة العربيـة يركـزون على تعزيـز القيم والهوبـة الوطنيـة لــدى طـلاب المرحلـة المتوسطة بمحافظة رنيـة بالمملكة العربيـة السعودية، وربمـا تعود هذه النتائج المنوافقة مع التوجهات التربوية في المملكة العربية السعودية في التركيز على

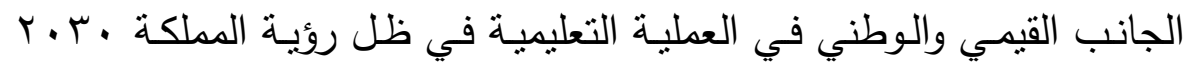


حوليتّكليت اللغت العربيت بايتاي البارود (العدد الثالث والثلاثون)

إضافة إلى الجانب المعرفي، وإلى وعي معلمي اللغة العربية بأهمية تعزيز قيم الولاء والانتماء والهوبة الوطنية لدى الطلاب. كما يعزو الباحث سبب حصول بعد الانتماء الوطني والهوية الوطنية على أعلى متوسط حسابي بلغ ( 9. ب)، ربمـا يعود إلى أن المهمـة الأساسـية لمعلمي اللغـة العربيـة تتمثل في غرس الانتماء والولاء والهوبة الوطنية لدى الطلاب، وتعميق الثعور بالحس الوطني والمواطنـة الصـالحة لـديهم. بالإضـافة إلىى أن توجهـات النظـام التربـوي في المملكة العربيـة السـودية في السـوات الأخيرة والمنطلقة مسن محساور الرؤيسة والتي ركزت على هذا البعد من خلال المؤسسات التربوبة المتخصصة وغير المتخصصة وبشكل معمق في التعليم الرسمي وفي مؤسسات التربية الموازبة. وكذللك فإن وجود موضوعات دراسية تتتاول التربية والهوبية الوطنبة وتعميقها لدى الطلاب قد ساهم في زبادة مساهمة المعلمين في التركيز على هذا البعد الوطني المهم.

أمـا فيمـا يتعلق ببعد "المسؤولية الوطنيـة تجـاه المجتمـع"، والذي حصـل على متوسط حسابي بلغ (19. ب) وهو أعلى من المستوى المقبول تربوياً، فقد يعود إلى أن الاهتمـام بهذا البعد قد نـال جزءاً كبيراً من الاهتمـام مـن قبـل مؤسسـات إعداد وتدريب معلمي اللغـة العربيـة وتأهيلهم، كذللك تضـمن كتب اللغــة العربيـة لموضـوعات وأنشـطة تعليميـة تتاولـت مختلـف أبعـاد الجانـب الاجتماعي والوطني بما بنسجم مع توجهات وتطلعات المجتمع السعودي، مما عزز من دور المعلم للقيام بتتميـة سلوكيات المسؤولية الوطنية تجاه المجتمع لدى الطلاب. أما بعد "الالتزام بمعايير وقيم المجتمع"، فقد حصل على منوسط حسابي بلغ (NV. r. وهو أعلى من المستوى المقبول تربوباً أيضـا؛ وهذا بشير إلى أن معلمي اللغـة العربية " يركزون بدور فعال في إكساب الطـلاب معـايير وقيم المجتمع، من خلال تقديم الأنشطة والفعاليات المدرسة التي تعزز لدى الطلاب 


\section{حوليتشكليت اللغت العربيتشبايتاي البارود (العدد الثالث والثلاثون)}

قيم الالتزام بمعايير وقيم مجتمعهم تمثالًا وممارسة، وهذا يعود إلى الأهمية التي تعطى لمعايير وقيم المجتمع السعودي باعتباره امتداداً لمعابير وقيم الأسرة السعودية المحافظة، مما ساعد معلمي اللغة العربية على تعزيزها لدى طلاب المرحلة المتوسطة بمحافظة رنية بالمملكة العربية السعودية. تتفق هذه النتيجة مع نتيجة دراسة كل من: ( الزيود والخوالدة، V . . Y؟؛

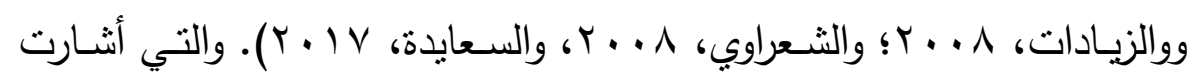
إلى أن درجة تركيز المعلمين على تعزيز المفاهيم الوطنية والقيم الاجتماعبة

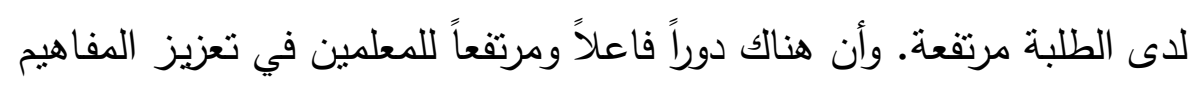
الوطنية والانتماء الوطني لدى الطلاب في المراحل التعليمية المختلفة. إلا إنها

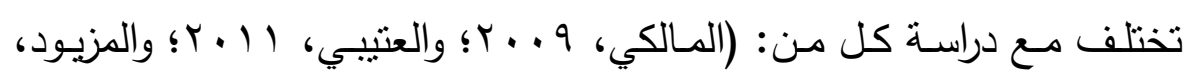
1 • (Y). والتي بينت أن درجة تركيز المعلمين على تعزيز المفاهيم الوطنية والقيم الاجتماعية لدى الطلبة متوسطة. التوصيات والمقترحات:

بناء على النتائج التي توصلت إلبها الدراسة فإن الباحثون يوصون بما بأتي: - الاستمرار بالإعداد الجيد لمعلمي اللغة العربية والمواد الدراسية الأخرى من أجل تعميق روح المواطنة لدى الطلاب في المراحل التعليمبة المختلفة.

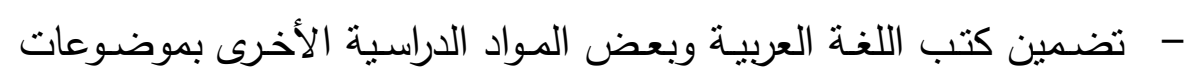
تعليمية وطنية تعزز روح الولاء والاتتماء للوطن وللأمة. - إجراء مزبد من الدراسات التي تتعلق بدور المدرسـة والأسرة في تعزبز قيم الولاء والانتماء للوطن، وتعزيز المسؤولية الاجتماعية لاى الطلاب. - إجراء دراسات مماثلة على معلمي ومعلمات مواد دراسية أخرى لها علاقة بتعزبز القيم الوطنية والهوبة الوطنبة لدى الطلبة، كمادة التربية الوطنبة، والتربية الإسلامية. 
حوليتة كليت اللغت العربيت بايتاي البارود (العدد الثالث والثلاثون)

\section{المراجع}

() إدعيس، احمـد والكسـاب، علي. (1 ( • (1). درجـة امـتلاك طلبـة معلم صف في الجامعات الأردنيـة للمهارات الاجتماعيـة من وجهة نظرهم.

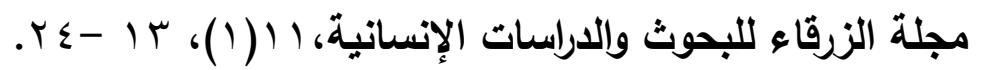
r) إسماعيل، محمد المري محمد، وشحاته، غادة أحمد(ب ا • r). الانتماء الوطني لدى طلاب جامعة الزقازيق بعد ثورة هب بناير . مجلة كليـة

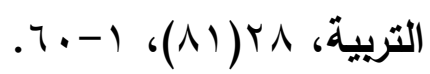

r) اقصبعة، عبد الرحمن احمد.(1 . . r). مستوى اكتساب بعض المفاهيم التاريخية الفلسطينية محافظات غزة وعلاقتها بانتمائه الوطني. رسالة

ماجستير غير منشورة، كلية التربية، الجامعة الإسلامية، غزة. ع) الثبيتي، محمد عثمان. ( 10 • ( ). دور إدارة الجامعة في تتمية قيم المواطنة لدى طلبة جامعة تبوك. مجلة جامعة طيبة للعلوم التربويـة،

$$
. r \vee \cdot-r \leqslant q \cdot(r) 11
$$

0) جابر، محمد، وناصر مهدي. (1) (ب). دور الجامعات في تعزيز مفاهيم المسؤولية الاجتماعيـة لاى طلبتها. مجلة كلبة التربية، جامعة

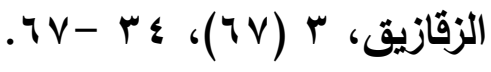

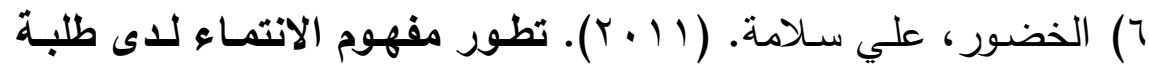
المـدارس الأسـاسية الأردنيـة. أطروحة دكتوراه غير منشورة، الجامعة

$$
\text { الأردنية، عمان، الأردن. }
$$

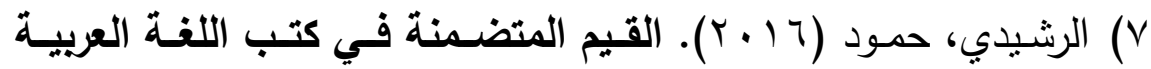
للمرحلة المتوسطة بالسعودية. رسالة ماجستير غير منشورة، الجامعة الأردنية، عمان.

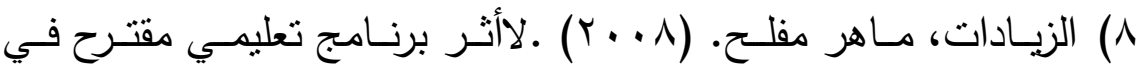
اكتساب طلبة الصف العاشر الأساسي للمفاهيم الديمقراطية في مبحث. 


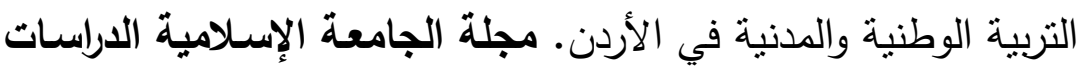

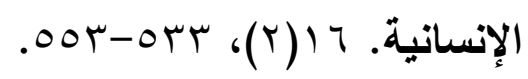

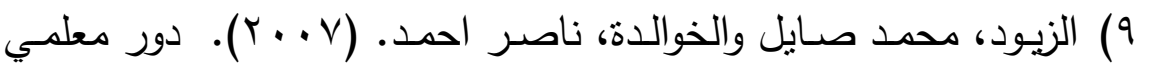

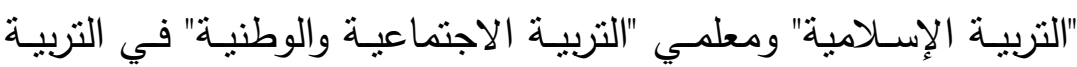

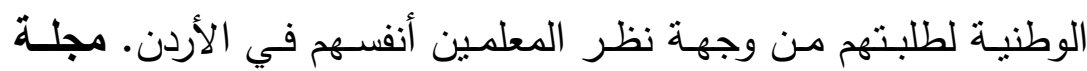

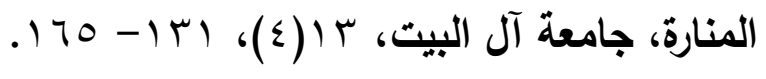

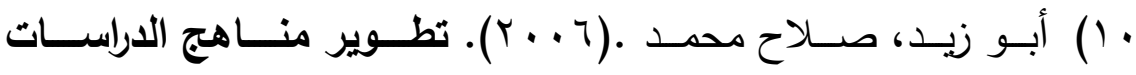
الاجتماعيـة للحلقـة الأولـى مسن التعلـيم الأساســي في ضـوء مفهـوم

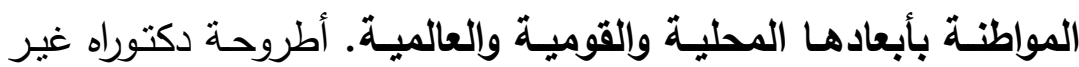
منشورة، جامعة الفيوم. - مان. (1) السـرحان، محمـود. (ع ( • (Y). الثـباب والاعتزاز الـوطني. سلســلة التثقيف الثبابي. عمان: المجلس الأعلى للثباب.

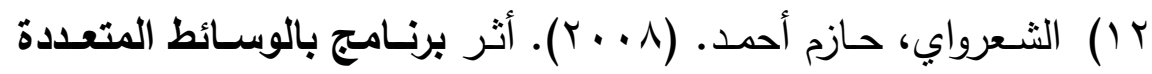

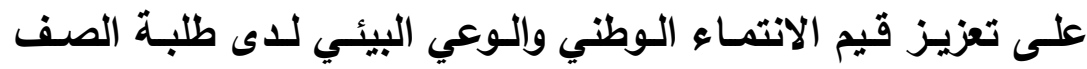

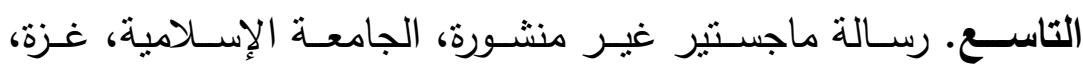
فلسطين.

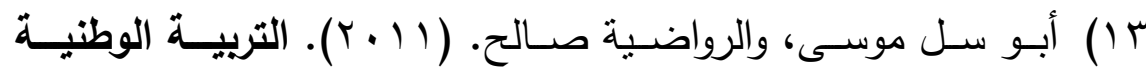
والمدنية في الأردن. عمان: مطابع عمان الوطنية.

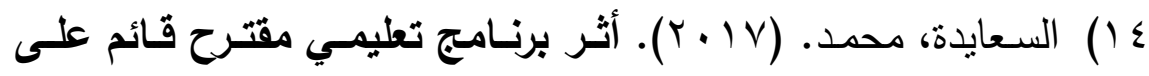
المهارات الاجتماعيـة في اكتسـاب مفاهيم الانتمـاء الوطني وممارسـة السـلوك الـايمقراطي في مبحث التربية الوطنيـة والمدنيـة لـى طلاب الصـف العاثـر الأساسـي فـي الأردن. رسـالة دكتوراه غيـر منشـورة،

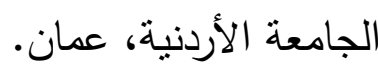


حوليتة كليتتا اللغت العربيت بإيتاي البارود (العدد الثالث والثلاثون)

10) السبد، عبد الفتاح جودة. ( • ( ب). دور الجامعة في توعية الطلاب

بمبـادى المواطنــة كمــدخل تحتمــهـ التحـديات العالميــة المعاصــرة : التعديلات الدستوربة للعام V . . r نموذجاً. مجلة كلية التربيـة، جامعة

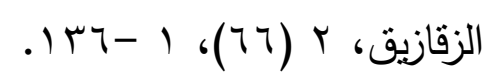

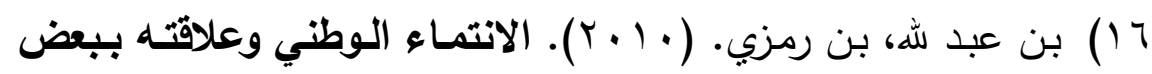
متغيرات الشخصية لاى عينة من طلاب المرحلة الثانوية بمدينتي مكة المكرمة وجدة. رسالة ماجستير (غير منثورة)، كلية التربية، جامعة أم القرى، المملكة العربية السعودية.

IV الـوطني لـدى التلاميـذ في المرحلـة الابتدائيـة، مكتبـة منهـل التقافـة التربوبة، قسم الثقافة العلمية. 1 1) العظامات، خديجة.(Y ( ( )، درجة ممارسة معلمي التربية الإسلامية في المرحلـة الثاتويـة لمبادئ الايمقراطيـة في التـديس الصـفي في قصبة المفرق. رسالة ماجستير غبر منشورة، جامعة آل البيت. الأردن.

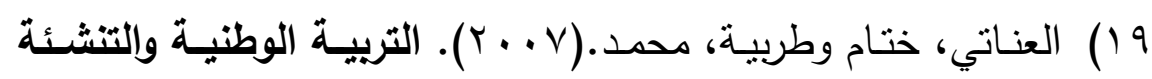
السياسية. عمان: دار الحامد للنشر . •

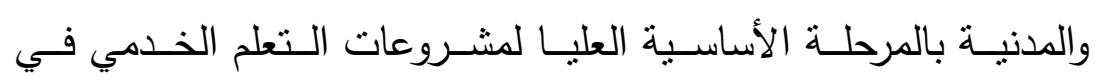
التدريس، ومعرفة أهم المعيقات التي تحول دون تتفيذها ،المجلة الأردنية

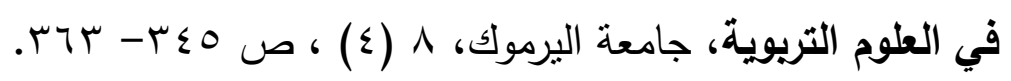

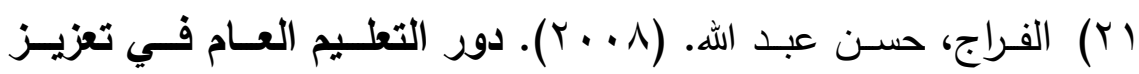
الانتمـاء الـوطني. أطروحة دكتوراه غير منشورة، جامعة نايف العربية للعلوم الأمنية الرباض، السعودية. 
حوليته كليت اللغتا العربيت بإيتاي البارود (العدد الثالث والثلاثون)

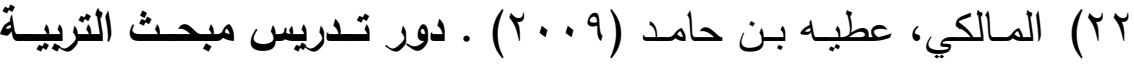

الوطنية في أكتساب قيم المواطنة لدى طلاب المرحلة الابتدائية دراسـة من وجهة نظر معلمي التربية الوطنية بمحافظة الليث. رسالة ماجستير غير منشورة، كلية التربية، جامعة أم القرى بمكة المكرمة.

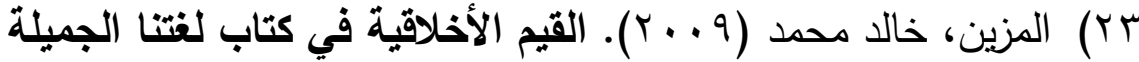

في المرحلة الأساسية الدنيا ومدى اكتساب طلاب الصف الرابع لها. رسالة ماجستير غير منشوره، الجامعة الإسلامية، غزة.

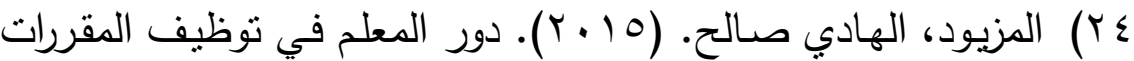

الدراسـية لاكتسـاب الانتمـاء الـوطني. مجلـة جامعـة الزيتونـة، ليبيـا،

$$
.0 Y 9-\varepsilon) \cdot v(10) \xi
$$

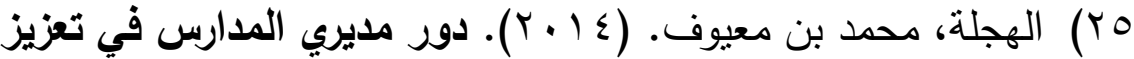
الانتمـاء الوطني لـى طلاب المـارس الثانويـة في المدينـة المنورة، رسالة ماجستير غير منشورة، جامعة طيبة، السعودية.

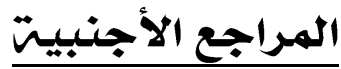

26) Eid. Fatima, H. (2015)، Citizenship، community and national identity: young people perceptions in a Bahraini context، Journal of Case Studies in Education، V. 7، 1-22.

27) Boulton, B,. (2008). Development of the Democratic Education Environment Scale، International Online Journal of Educational Sciences، 2013، 5 (1)، 82-98.

28) Petrsoon، J. (2009).Appraisal of Middle School Students' Participation in a Social Skills Training Program. Unpublished dissertation. Union Institute and University.ohio.USA. 
مدى تركيز معلمي اللغت العربيت على القيم والهويت الوطنيت وتعزيزها لدى طلاب المرحلتة

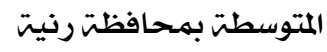

حوليت كليتا اللغت العربيت بإيتاي البارود (العدد الثالث والثلاثون)

29) Boulton, G. and Lucas, C. (2008). What Are Universities for?, Amsterdam, League of European Research Universities.

30) Larasquet, J. and Pilniere, V. (2012). Seeking a Sustainable Future: The Role of University. International Journal of Technology Management and Sustainable Development, 11 (3), 34 -54. 